\title{
Genome-wide methylation analysis reveals differentially methylated loci that are associated with an age-dependent increase in bovine fibroblast response to LPS
}

Filiz T. Korkmaz ${ }^{1,2^{*}}$ and David E. Kerr ${ }^{1,2}$

\begin{abstract}
Background: Differences in DNA methylation are known to contribute to the development of immune-related disorders in humans but relatively little is known about how methylation regulates immune function in cattle. Utilizing whole-transcriptome analyses of bovine dermal fibroblasts, we have previously identified an age and breed-dependent up-regulation of genes within the toll-like receptor 4 (TLR4) pathway that correlates with enhanced fibroblast production of IL-8 in response to lipopolysaccharide (LPS). Age-dependent differences in IL-8 production are abolished by treatment with 5-aza-2-deoxycytidine and Trichostatin A (AZA-TSA), suggesting epigenetic regulation of the innate response to LPS. In the current study, we performed reduced representation bisulfite sequencing (RRBS) on fibroblast cultures isolated from the same animals at 5- and 16-months of age to identify genes that exhibit variable methylation with age. To validate the role of methylation in gene expression, six innate response genes that were hyper-methylated in young animals were assessed by RT-qPCR in fibroblasts from animals at different ages and from different breeds.

Results: We identified 14,094 differentially methylated CpGs (DMCs) that differed between fibroblast cultures at 5- versus 16-months of age. Of the 5065 DMCs that fell within gene regions, 1117 were located within promoters, 1057 were within gene exons and 2891 were within gene introns and 67\% were more methylated in young cultures. Transcription factor enrichment of the promoter regions hyper-methylated in young cultures revealed significant regulation by the key pro-inflammatory regulator, NF-KB. Additionally, five out of six chosen genes (PIK3R1, FES, NFATC1, TNFSF13 and RORA) that were more methylated in young cultures showed a significant reduction in expression post-LPS treatment in comparison with older cultures. Two of these genes, FES and NFATC1, were similarly down-regulated in Angus cultures that also exhibit a low LPS response phenotype.
\end{abstract}

Conclusions: Our study has identified immune-related loci regulated by DNA methylation in cattle that may contribute to differential cellular response to LPS, two of which exhibit an identical expression profile in both low-responding age and breed phenotypes. Methylation biomarkers of differential immunity may prove useful in developing selection strategies for replacement cows that are less susceptible to severe infections, such as coliform mastitis.

Keywords: DNA Methylation, Innate Immunity, LPS, Inflammation, RRBS

\footnotetext{
*Correspondence: Filiz.Korkmaz@uvm.edu

${ }^{1}$ Cellular, Molecular and Biomedical Sciences Program, University of Vermont,

89 Beaumont Avenue, C141C Given, Burlington, VT 05405, USA

${ }^{2}$ Department of Animal and Veterinary Sciences, University of Vermont, 570

Main Street, 213 Terrill Hall, Burlington, VT 05405, USA
} 


\section{Background}

The innate immune response is an organism's first line of defense against pathogenic microorganisms and the primary response to tissue damage. Innate immunity is mediated by specialized leukocytes and cells that serve as a barrier to the environment, such as epithelial cells and dermal fibroblasts. Innate immune cells are characterized by their expression of germ-line encoded pattern recognition receptors (PRRs) which recognize conserved molecular patterns (PAMPs), such as lipopolysaccharide found on the outside of Gram-negative bacteria and viral nucleic acids, and elicit the appropriate defense response upon recognition. The most thoroughly characterized of these PRRs are Toll-like receptors (TLRs), a family of type-I transmembrane proteins first discovered in Drosophila melanogaster when the Toll gene was found to be essential for bacterial and fungal defenses [1, 2]. Upon TLR-ligand binding, an intracellular signaling cascade is activated which allows for the transcription of numerous pro-inflammatory proteins, such as IL-6, TNF- $\alpha$ and IL1- $\beta$, through the action of transcription factors NF- $k B$, $\mathrm{AP}-1$ and Interferon Response Factors (IRFs), among others [3]. While it is clear that the response elicited by TLRs and other PRRs are crucial to the defense against a variety of bacterial, viral and eukaryotic pathogens [4-6], an exacerbated or dysregulated innate response also contributes to infection related inflammatory disorders, such as in antibody dependent enhancement and the subsequent "cytokine storm" characteristic of Dengue hemorrhagic fever [7]. In addition, the type I interferon response, normally beneficial to the host during a viral infection, has been shown to actually increase susceptibility to some bacterial, viral and protozoan infections [8]. The innate response is also a key contributor to a number of sterile pro-inflammatory conditions, such as rheumatoid arthritis and asthma $[9,10]$.

The severity of bovine mastitis, a primary cause of economic losses to dairy milk production, is similarly more often associated with increased production of proinflammatory mediators such as, TNF- $\alpha$, IL1- $\beta$ and IL-6, than it is with number of bacteria present within the mammary gland. Mastitis severity has also been shown to vary greatly, even under controlled experimental settings where pathogen factors are held constant. This suggests host factors play a significant role in mastitis outcome [11]. Several studies have shown a dysregulated population of milk and serum neutrophils, along with greater concentrations of TNF- $\alpha$ and reactive oxygen species, during the peri-partum period when animals are highly susceptible to severe mastitis [12]. Interestingly, priming of the mammary gland with $1 \mu \mathrm{g}$ of LPS, which causes a substantial but short lived inflammation, reduces severity of experimentally induced Escherichia coli (E. coli) mastitis 10 days post LPS priming [13]. In an effort to explain the mechanism behind this reduction in mastitis severity, a study by Gunther et al. [14] measured gene expression in response to heat killed $E$. coli in primary mammary epithelial cells following pretreatment with LPS. Priming of cells was found to increase expression of $ß$-defensins while decreasing proinflammatory and apoptotic gene expression, including IL1- 3 , TRAF6, and TNF superfamily proteins (TNFSF13B and TNFSF10), indicating that the previously measured benefit of LPS priming in an intra-mammary infection with $E$. coli was due in part to a reduction in inflammatory response [14]. In a murine mastitis model, administration of LPS into the mammary gland of TLR4(-/-) mice to induce mastitis showed that while knockout mice had significantly lower serum cytokines CXCL1, IL1-ß, IL-6, IL-10, TNF- $\alpha$, CCL2 and IP10, they also experienced a lower degree of mammary gland involution and maintained increased capacity for milk production as compared to wild-type littermates [15]. In agreement with aforementioned studies, our lab has shown that high responding dairy animals, based on dermal fibroblast IL-8 production in response to TLR ligands, have greater tissue damage and neutrophil influx into the mammary gland postinfection and a slower return to pre-infection milk production levels in response to both Staphylococcus aureus (S. aureus) and E. coli mastitis, without any benefit to their ability to clear bacteria $[16,17]$.

Several factors, including genetic differences, may contribute to variation within an animal's infection response phenotype. In one example, single nucleotide polymorphisms in the TLR4 gene have been linked to increased susceptibility to Mycobacterium avium subspecies tuberculosis, or Johne's disease, in Canadian Holsteins [18]. However, a recent study between 3 breeds indicated an estimated heritability of clinical mastitis to be between 2 and $4 \%$, suggesting a very large role for non-genetic factors [19]. Epigenetic modifications, such as DNA methylation, may help to explain discrepancies measured between large phenotypic differences with little genetic basis. In agreement with this, DNA methylation in two breeds of chicken has been shown to contribute to differential susceptibility to infectious diseases such as avian flu and Salmonella. Whole genome bisulfite sequencing (WGBS) revealed greater than 5000 differentially methylated regions (DMRs) in lung tissue between the two breeds, with a portion of DMRs falling within gene regions. The methylation data generated by WGBS together with mRNA expression data generated by RNA-seq, also identified genes with both differential methylation and expression, most notably TLR4 and PIK3CD [20].

In support of epigenetic regulation of the bovine innate immune response, data generated in our lab has shown that an age-dependent increase in dermal fibroblast response to LPS is ameliorated following treatment 
with a DNA methylation and histone deacetylase inhibitor, AZA-TSA [21]. A subsequent study was done to identify methylation and gene expression differences in fibroblast cultures isolated from female calves at 5- and 16-months of age. Transcriptome-wide analysis of these two sets of cultures identified numerous genes within the TLR4 response pathway that were up-regulated in older, more responsive cultures, including TLR4, CD-14, IL-8 and TNF- $\alpha$ [22]. In the same study, we sought to identify changes in DNA methylation between the young and old cultures that contribute to age-related differences in innate immunity, however, the MIRA (methylated $\mathrm{CpG}$ island recovery assay)-seq technique that was utilized does not have the resolution required to determine methylation differences at the base pair level. As such, very little difference in methylation was found between the two sets of cultures.

Another phenotypic difference we have identified is the differential response between Holstein and Angus breeds, where Holstein cattle exhibit a much higher fibroblast response to LPS than Angus cattle. The few reports of mastitis in beef cows have also suggested beef breeds are less susceptible to coliform mastitis, with no cases of $E$. coli mastitis cases detected in several studies $[23,24]$. In this case, genetic differences between breeds are likely to have an influence, however, calves from these two breeds experience highly disparate upbringing. In contrast with Angus and other beef breeds, Holstein calves are immediately separated from their dam allowing for little to no maternal care which has been shown to contribute to differential methylation of hormone receptors in rats [25]. Again, transcriptome analysis of age-matched fibroblasts isolated from the two breeds revealed a number of pro-inflammatory genes with differential expression, with Holstein cultures exhibiting significant up-regulation as compared to Angus cultures. However, little to no difference in DNA methylation was found using the MIRA-seq technique [26].

Knowledge of epigenetic regulation of the immune response in dairy cattle is currently lacking and will be important to understanding differences in mastitis susceptibility. From the previous studies, it is clear that methylation differences at a base pair resolution are required. As such, the aim of the current study was to identify base-pair specific DNA methylation differences in fibroblasts taken from Holstein heifers at 5- and 16months of age using reduced representation bisulfite sequencing (RRBS). Once candidate differentially methylated genes were identified, we determined whether methylation effects gene expression by measuring fibroblast gene expression at various time points post-LPS treatment. Furthermore, we determined whether genes regulated by methylation in young and old cultures also differed in gene expression between Angus and Holstein cultures. Overall the current study contributes to our knowledge of candidate immune response genes that are subject to regulation by DNA methylation within the genome of dairy cattle and may lead to a better understanding of the mechanisms that regulate inter-animal variation in susceptibility to severe mastitis.

\section{Methods \\ Experimental animals}

Six pairs of dermal fibroblast samples, collected from Holstein heifers at 5 and 16 months of age, were used from a previously characterized cohort of 15 heifer fibroblast samples [27]. Primary dermal fibroblast collection and ranking based on IL-8 production following in vitro LPS stimulation was previously described [27]. The six pairs of fibroblast samples chosen for DNA methylation analysis were all selected from mid-responding animals to reduce inter-animal variation within the two groups that could potentially interfere with any true age effects.

A second set of dermal fibroblasts was collected for the breed difference experiments. Fibroblasts were isolated from four 19-month Holstein and four 19-month Black Angus cows. Fibroblast collection, isolation and LPS response are described elsewhere [26].

In both the age and breed experiments, fibroblasts were stimulated with $100 \mathrm{ng} / \mathrm{ml}$ of LPS and RNA isolation was performed side-by-side in neighboring wells. From the same vial of cryopreserved cells used in the LPS challenge, some cells were cultured in a T-75 $\mathrm{cm}^{2}$ culture flask for DNA isolation. Cells were again cultured side-by-side and untreated cultures were used for DNA extraction.

All experiments were approved by the Institutional Animal Care and Use Committee at the University of Vermont.

\section{Fibroblast culturing and LPS challenge}

Growth media for fibroblast cultures was Dulbecco's Modified Eagle Media (DMEM; Hyclone Laboratories, Logan, UT) supplemented with $5 \%$ fetal bovine serum (FBS; Hyclone Laboratories), 1\% penicillin-streptomycin (Hyclone Laboratories) and $1 \%$ insulin-transferrinselenium (ITS; Mediatech Inc., Herndon, VA). Fibroblasts were revived from cryopreservation and expanded in a T-75 $\mathrm{cm}^{2}$ culture flask at $37{ }^{\circ} \mathrm{C} 5 \% \mathrm{CO}_{2}$ in a humidified incubator. Confluent flasks were then treated with $0.25 \%$ trypsin (MP Biomedical, Santa Ana, CA) and cells were transferred to a 6 -well plate at $1.25 \times 10^{5}$ cells $/ \mathrm{ml}$ in a total volume of $2 \mathrm{ml}$, or $2.5 \times 10^{5}$ total cells and cultured for $24 \mathrm{~h}$ for the LPS challenge experiments. Remaining cells were transferred to a T-75 $\mathrm{cm}^{2}$ culture flask and allowed to grow to confluency for subsequent DNA isolation. 
After $24 \mathrm{~h}$, cells in the 6-well plates were treated with $100 \mathrm{ng} / \mathrm{ml}$ of ultra-pure LPS isolated from Escherichia coli O111.B4 (Sigma-Aldrich, St. Louis, MO) for either $0,2,8$ or $36 \mathrm{~h}$. At 0 and $36 \mathrm{~h}$, media was collected for protein production analysis. After removal from the wells, media was centrifuged at $10,000 \times \mathrm{g}$ for $1 \mathrm{~min}$ to remove cellular debris and stored at $-20{ }^{\circ} \mathrm{C}$ until further analysis. At every time point, cells were rinsed gently with Dulbecco's Phosphate Buffered Saline (DPBS; Hyclone Laboratories) and cell lysate was collected by adding $500 \mu \mathrm{l}$ cell lysis buffer (5 Prime, Hamburg, Germany) to the well. Cell lysate was stored at $-20{ }^{\circ} \mathrm{C}$ until RNA isolation.

Cells that were grown in a T-75 $\mathrm{cm}^{2}$ culture flask for DNA isolation were treated with trypsin at confluency and centrifuged at $400 \times \mathrm{g}$. The cell pellet was then lysed with $300 \mu \mathrm{l}$ cell lysis buffer (5 Prime) by adding the lysis buffer and vortexing for $15 \mathrm{~s}$. The cell lysate was stored at $-20{ }^{\circ} \mathrm{C}$ until DNA isolation.

\section{Quantification of IL-8 and IL-6 protein}

Interleukin- 8 production in media from LPS stimulated dermal fibroblasts was determined with a sandwich ELISA (Mabtech Inc., Cincinnati, $\mathrm{OH}$ ) per manufacturer's protocol with slight modifications. Capture antibody was diluted $1: 500$ to $1 \mu \mathrm{g} / \mathrm{ml}$ in $0.05 \mathrm{M}$ bicarbonate buffer. Recombinant bovine IL-8 (Thermo Scientific, Rockford, IL) was used as the assay standard with a detection limit of $156.25 \mathrm{pg} / \mathrm{ml}$. Capture antibody was diluted $1: 20,000$ in PBS-0.05\% Tween-20 to a concentration of $0.025 \mu \mathrm{g} / \mathrm{ml}$. Streptavidin-horseradish peroxidase was diluted $1: 15,000$ in PBS-0.05\% Tween-20 to a concentration of $0.07 \mu \mathrm{g} / \mathrm{ml}$.

Interleukin-6 production was also determined by a sandwich ELISA (Thermo Scientific) per manufacturer's instructions. Briefly, capture antibody was diluted 1:100 in $0.05 M$ bi-carbonate buffer. Recombinant bovine IL-6 (Thermo Scientific) was used as the assay standard with a detection limit of $156.25 \mathrm{pg} / \mathrm{ml}$. Detection antibody was diluted $1: 100$ in PBS-0.1\% BSA. Streptavidinhorseradish peroxidase (Sigma-Aldrich) was diluted 1:2000 in PBS-0.1\% BSA to a concentration of $0.5 \mu \mathrm{g} / \mathrm{ml}$. Development of IL-8 and IL-6 ELISA plates was done by adding 3,3,5,5'-tetramethylbenzidine substrate (TMB; Thermo Scientific) to the wells and the reaction stopped with $1 \mathrm{M} \mathrm{H}_{2} \mathrm{SO}_{4}$.

\section{DNA extraction and preparation for RRBS}

DNA was extracted from 5- and 16- month dermal fibroblasts using a 5-Prime PerfectPure ${ }^{\mathrm{TM}}$ Archive DNA Extraction Kit (5 Prime) per manufacturer's protocol. DNA concentrations were then determined using a Qubit $^{\mathrm{TM}}$ 2.0 Spectrofluorometer (Life Technologies, Carlsbad, CA). DNA was diluted to $40 \mathrm{ng} / \mu \mathrm{l}$ and a total of $2 \mu \mathrm{g}$ was sent to Zymo Research (Irvine, CA) for Methyl-MiniSeq ${ }^{\text {TM }}$ RRBS library preparation. Libraries were generated with 200-500 ng of DNA as previously described [28]. Briefly, DNA was sequentially digested with 60 units of Taqd and 30 units of MSPI (NEB, Ipswich, MA) which recognizes CCGG as a cut site and cleaves after the first cytosine, creating DNA products with CG dinucleotides on both ends of the DNA and enriching for CG rich regions. Following enzymatic digestion, DNA products were end-repaired, A-tailed and extracted with DNA Clean and Concentrator Kit ${ }^{\mathrm{TM}}$ (Zymo Research). The extracted DNA was then ligated to methylated Illumina primers using the Illumina DNA preparation kit and protocol (Illumina, San Diego, CA). Adaptor ligated DNA was then size selected for desired input fragments (150-250 bp and 250-350 bp) with a $2.5 \%$ NuSieve 3:1 agarose gel and extracted using the Zymoclean ${ }^{\mathrm{TM}} \mathrm{Gel}$ DNA Recovery Kit (Zymo Research). Successfully ligated and purified DNA was then bisulfite converted using the EZ DNA Methylation-Lightning ${ }^{\mathrm{TM}}$ Kit (Zymo Research). Control DNA was similarly bisulfite converted to assess conversion rates, which were $99 \%$ for all samples. Following conversion, preparative-scale PCR was performed with a total of 16 cycles and PCR products were purified with the DNA Clean and Concentrator Kit ${ }^{\mathrm{TM}}$ (Zymo Research). DNA libraries were then sequenced on the Illumina HiSeq2000 (Illumina), generating 50 bp paired-end reads and base-calling was performed using standard Illumina base-calling software.

\section{DNA sequence processing and alignment}

Following sequencing, bioinformatics analysis was performed at Zymo Research using a proprietary analysis pipeline written in Python. Prior to alignment, reads were assessed for quality using FastQC (v0.11.1, Babraham Bioinformatics, UK) and Trim Galore (v0.3.7, Babraham Bioinformatics, UK). Bases with a Phred score greater than 20 were kept for downstream analysis (-paired -phred33 - q 20). Illumina adaptor trimming was done using Trim Galore with the default settings which are automatically set to standard Illumina adaptors unless otherwise specified. Trim Galore also contains a setting specifically for trimming RRBS data $(--r r b s)$ which was used to further modify our reads. RRBS introduces artificial $\mathrm{CpG}$ sites which require trimming in order to avoid them being used in methylation calling. To do so, Trim Galore trims the first 2 bases from the 3' end of the sequence so the $\mathrm{C}$ closest to the second enzyme cut site is not included in methylation calling. Reads were then mapped to an in-silico bisulfite converted reference genome (BosTau8/BTau_4.6.1) with the Babraham Bismark software (v0.13.1, Babraham Bioinformatics, UK) using the bismark_genome_preparation command, the entire reference genome and with the -non_directional 
parameter applied. Babraham Bismark is designed for aligning bisulfite sequencing data while simultaneously making methylation calls. In the process of bisulfite sequencing, un-methylated cytosines are converted to uracil, while methylated cytosines are unaffected. The result of this is four sets of potential sequences at any given locus. To determine which of these four potential sequences is correct, Bismark creates two bisulfite converted reference genomes, one that is a $\mathrm{C} \rightarrow \mathrm{T}$ conversion and one that is a $\mathrm{G} \rightarrow \mathrm{A}$ conversion to account for conversion on the reverse strand. Each sequence read is also bisulfite converted in silico and is aligned to the pre-converted version of the reference genome. The best alignment is then identified and used to make a methylation call. Alignments that are uniquely mapped were kept for analysis. Alignments that mapped to multiple regions were discarded. Due to enrichment-constraints of RRBS libraries, duplicates measured as a result of shorter, overlapping paired end inserts were not removed in the sequence data and were counted as two reads.

On average, mapping efficiencies were $25 \%$ and ranged between 23 and $27 \%$ and the average number of unique CpGs identified were 6.0 million and ranged between 4.8 and 6.6 million. Differentially methylated CpGs falling within $-2.5 \mathrm{~kb},+1.0 \mathrm{~kb}$ of an annotated transcription start site (TSS) were defined as being within the promoter region of a gene. Methylation ratios were used as the comparison parameter to test statistical differences in DNA methylation and these were defined as the number of reads overlapping a particular CpG site which contained either a cytosine or thymine nucleotide. Ratios were then calculated as Methylation Ratio $(\mathrm{Mr})=(\mathrm{C}) /(\mathrm{C}+\mathrm{T})$.

\section{Functional analysis}

KEGG (Kyoto Encyclopedia for Genes and Genomes) pathway, GO (Gene Ontology) and UCSC (University of California Santa Cruz) Transcription Factor Binding Site (TFBS) analyses were performed using the DAVID (the Database for Annotation, Visualization, and Integrated Discovery) 6.8 platform [29, 30]. Four lists of official gene IDs (all IDs or promoter only with $\geq 5 \times$ or $\geq 10 \times$ coverage) were generated for sites located within annotated genes that were hyper-methylated in either young or old cultures (Additional files 1 and 2). A suggestive analysis was performed on all differentially methylated genes with $\geq 5 \times$ coverage and a conserved analysis was performed with only genes that had $\geq 10 \times$ coverage. Gene IDs from all three gene regions (exon, intron and promoter) were inputted into DAVID, converted to Entrez gene IDs and default parameters were used for KEGG and GO analyses. Only those genes that were covered by RRBS, either at the $5 \times$ or $10 \times$ level, were set as the background. Promoter gene IDs were used in transcription factor enrichment analysis and TFBS analysis was similarly run with default parameters and Homo sapiens as the background due to a lack of support for Bos taurus within the UCSC_TFBS tool.

\section{Gene expression of selected genes}

Selected differentially methylated genes and LPS response genes were measured in all fibroblast cultures exposed to LPS for 0,2 and $8 \mathrm{~h}$. RNA was isolated using the 5 Prime PerfectPure ${ }^{\mathrm{TM}}$ RNA Cultured Cell Kit (5 Prime) per manufacturer's instructions and quantified using a $\mathrm{Qubit}^{\mathrm{TM}}$ 2.0 Fluorometer (Life Technologies, Carlsbad, CA). First strand cDNA synthesis was done using the ImpromII ${ }^{\mathrm{TM}}$ Reverse Transcriptase Kit (Promega, Madison, WI). To determine gene expression, quantitative reverse transcriptase PCR (RT-qPCR) was performed using Thermo Scientific $^{\mathrm{Tm}}$ Maxima $^{\mathrm{Tm}}$ SYBR $^{\mathrm{Tm}}$ Green/Fluorescein 2× qPCR Master Mix (Thermo Fisher) on a CFX96 Touch $^{\text {Tx }}$ RealTime PCR machine (Biorad, Hercules, CA) on the selected genes. The gene $\beta$-Actin was used as a housekeeping gene control. Cycling conditions were as follows: $95{ }^{\circ} \mathrm{C}$ for $2 \mathrm{~min}$ followed by 40 cycles of $95{ }^{\circ} \mathrm{C}$ for $15 \mathrm{~s}$, $60{ }^{\circ} \mathrm{C}$ for $1 \mathrm{~min}$ and $72{ }^{\circ} \mathrm{C}$ for $1 \mathrm{~min}$ after which a melt curve was inserted. All oligonucleotide primer sequences are shown in Table 1 . Unless already published primers were available, all primers were designed using Primer 3 on NCBI. An amplicon of $200-300$ base pairs was designed and the primer binding site could not contain any known SNP. Each primer sequence was then analyzed with an NCBI nucleotide BLAST search to ensure only the intended Bos taurus gene was detected. Melt curve analysis was performed on each primer pair and included a negative control reaction (no cDNA). Melt curve analysis revealed only one peak indicative of a single product with no peaks associated with the negative control.

\section{Statistical analysis}

To assess differences in cytokine protein production a paired Student's $t$ test was performed using GraphPad Prism Version 6.0 for Windows (GraphPad Software, La Jolla, CA). Differences in DNA methylation at adequately covered ( $\geq 5 \times$ coverage based on similar RRBS studies [31, 32]) CpG sites was performed at Zymo Research and determined using a paired Student's $t$ test comparing methylation ratios at each site. A clustering dendogram was made according to methylation ratio on the top 100 differentially methylated sites, based on $p$-value. The clustering analysis was performed at Zymo Research using a standard data analysis algorithm with a "complete" linkage method and a "Euclidean Distance" metric. Significance for GO, KEGG and TFBS were determined by a modified Fisher's Exact test in DAVID as previously described [29] and multiple comparisons correction were done using the Benjamini- 
Table 1 Real time PCR primers

\begin{tabular}{|c|c|c|}
\hline Gene name & Sequence $5^{\prime}$ to $3^{\prime}$ & Reference \\
\hline$\beta$-Actin & $\begin{array}{l}\text { F: GCAAATGCTTCTAGGCGGACT } \\
\text { R: CAATCTCATCTCGTTITCTGCG }\end{array}$ & [84] \\
\hline Feline Sarcoma Oncogene (FES) & $\begin{array}{l}\text { F: GTCTCAGACAAGTCCCCGTG } \\
\text { R: AGTCTGAACACAGCGTCAGG }\end{array}$ & Designed in house \\
\hline Interleukin 6 (IL6) & $\begin{array}{l}\text { F: TGAGGGAAATCAGGAAAATGT } \\
\text { R: CAGTGTTTGTGGCTGGAGTG }\end{array}$ & [84] \\
\hline Interleukin 8 (IL8) & $\begin{array}{l}\text { F: GCTGGCTGTTGCTCTCTTG } \\
\text { R: AGGTGTGGAATGTGTITTATGC }\end{array}$ & [84] \\
\hline Nuclear factor of activated T-cells calcineurin dependent 1 (NFATc1) & $\begin{array}{l}\text { F: GTCCGACGTCAAGCGGTAG } \\
\text { R: TTGACCGTTACGGGAATGGG }\end{array}$ & Designed in house \\
\hline Phosphatidylinositol 3-kinase regulatory subunit alpha (PIK3R1) & $\begin{array}{l}\text { F: TCATTCCGGTAGCCGTTTCC } \\
\text { R: CTCAGAACTTGCTGCTGGGA }\end{array}$ & Designed in house \\
\hline RAR-Related Orphan Receptor A (RORA) & $\begin{array}{l}\text { F: ATAACATCTCGGCCAACGGG } \\
\text { R: GGAAGAAGCCTGATGCTGGT }\end{array}$ & Designed in house \\
\hline Transcription factor 7 (T-cell specific, HMG-box) (TCF7) & $\begin{array}{l}\text { F: GAGCCAAAGTCATTGCGGAG } \\
\text { R: TCTITITCCTCCTGAGTTGGATTC }\end{array}$ & Designed in house \\
\hline Tumor Necrosis Factor Super Family 13 (TNFSF13) & $\begin{array}{l}\text { F: AGAAGCGCTCAGTTCTGCAT } \\
\text { R: CTGTTGTAGGCCCAGTCAGG }\end{array}$ & Designed in house \\
\hline
\end{tabular}

Hochberg method. Gene expression differences were determined using either a paired (young vs. old) or unpaired (Angus vs. Holstein) Student's $t$ test at each time point in GraphPad. Protein concentrations and delta $\mathrm{Ct}$ values are expressed as the mean $+/$ - standard error (SEM).

\section{Results}

\section{Fibroblast cytokine response to LPS}

Dermal fibroblasts from the same six animals taken at 5 and 16 months of age were revived from cryopreservation for a total of 12 cultures (6 young vs. 6 old). Cultures were subsequently stimulated with LPS (100 ng/ $\mathrm{ml}$ ) for $36 \mathrm{~h}$ to determine cytokine protein concentration in the media. Media from unstimulated cultures was used as a negative control. Protein concentrations of interleukin-8 (IL-8) are shown in Fig. 1, panel a. As expected, the 16-month cultures produced significantly more IL-8 $(P<0.01)$ than the 5 -month cultures. At $36 \mathrm{~h}$, older cultures had an approximately 5 -fold higher concentration of IL-8 than young cultures. No detectable IL- 8 was produced in media only controls. Interleukin-6 (IL-6) was also measured in media post 36-h LPS stimulation. In line with IL-8 protein, 16-month cultures produced significantly more IL-6 $(P<0.01)$ than 5-month cultures (Fig. 1, panel b). This difference in older cultures was about 2.5-fold more IL- 6 than young cultures. Again, control media IL-6 levels fell below detection limits of this assay.

Next, to determine if cytokine gene expression was also different between the young and old cultures, RT-qPCR was performed on fibroblasts at 0,2 and $8 \mathrm{~h}$ post LPS stimulation. In line with protein production, IL8 and IL6 gene expression levels were upregulated $(P<0.01)$ in old versus young cultures (Fig. 1, panels c and d). Older fibroblast cultures had a 15.9 and 10.9-fold increase in IL8 gene expression and a 7.3 and 13.4-fold increase in IL6 gene expression over younger cultures at 2 and $8 \mathrm{~h}$ post LPS stimulation, respectively.

Cytokine protein and expression analyses confirmed that the older dermal fibroblast cultures were much more responsive to LPS than younger cultures. Genomic DNA was then isolated from unstimulated cultures, grown from the same cryopreserved stock used to assess LPS response, and analyzed by RRBS to determine whether methylation differences may contribute to differences in the LPS-induced response.

\section{Reduced representation bisulfite sequencing in 5-month and 16-month dermal fibroblasts}

As outlined in the RRBS project workflow in Fig. 2, genomic DNA from all the cultures were treated with a methylation insensitive restriction enzyme MSPI. The restriction enzyme cuts at CCGG sites, following the first cytosine, yielding CG sites on both ends of the resulting DNA fragments. This results in enrichment of fragments from regions in the genomic DNA with many CpG sites, such as CpG islands, that are typically associated with promoter regions of DNA [33]. In our analysis, $65 \%$ of annotated promoter regions, defined as -2500 to +1000 bp from the transcription start site (TSS) had greater than $50 \times$ coverage, $8 \%$ had less than $50 \times$ but greater than $10 \times$ coverage, $4 \%$ had less than $10 \times$ coverage and $23 \%$ were not represented.

Following bisulfite conversion, sequencing and postsequencing bioinformatics, a paired T-test was performed on the methylation ratios between young and old cultures 
a

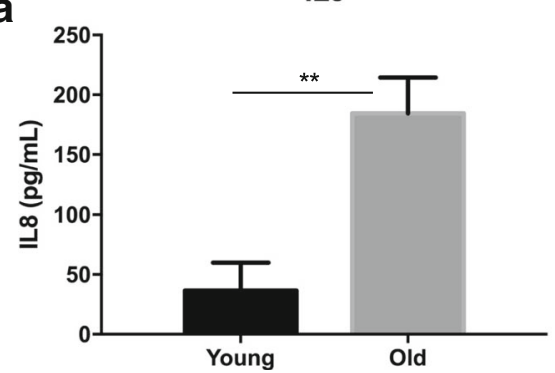

C

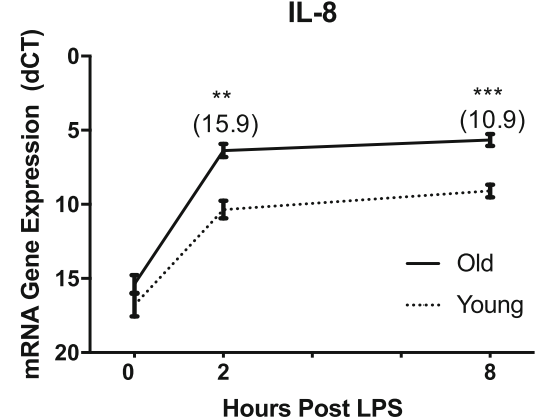

b

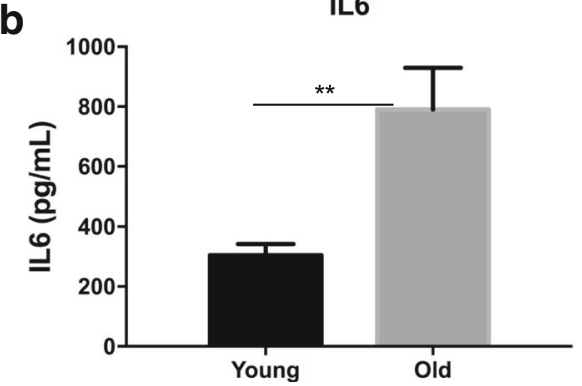

d

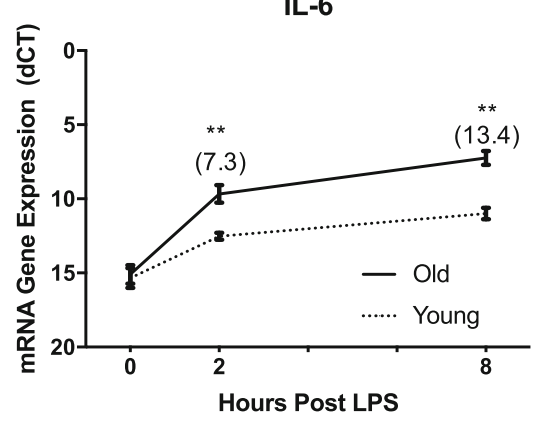

Fig. 1 Fibroblast Response to LPS in Young versus Old Cultures. Interleukin-8 (a \& c) and Interleukin-6 (b \& d) protein production and gene expression were measured in young and old dermal fibroblasts ( $n=6$ per group) at various time points post LPS. Protein production is presented in $\mathrm{pg} / \mathrm{ml}$ following $36 \mathrm{~h}$ of LPS stimulation. Gene expression was measured by RT-qPCR and is presented as the change in cycles to threshold (dCT) of gene expression at 0,2 \& 8 h post LPS in comparison to $\beta$-actin. Fold change gene expression (Old > Young) is presented in parentheses above each significant time point. All values are displayed as mean (+/- SEM). Significance was measured using a paired Student's test at each time point and ${ }^{* *}=P<0.01^{* * *}=P<0.001$

\begin{tabular}{|c|c|}
\hline Prior to RRBS & $\begin{array}{l}\text { - Sample Selection (6 young vs. } 6 \text { old DFs) } \\
\text { - LPS Challenge of DFs (0, 2, } 8 \text { \& } 36 \mathrm{H} \text { ) } \\
\text { - IL8 and IL6 protein \& gene expression }\end{array}$ \\
\hline Preparation of DNA & $\begin{array}{l}\text { - MSPI Digestion } \\
\text { - End Repair \& Poly-A tail } \\
\text { - Illumina primer ligation \& size selection } \\
\text { - Bisulfite Conversion } \\
\text { - Sequencing (Illumina HiSeq 2000) }\end{array}$ \\
\hline $\begin{array}{r}\text { Post RRBS } \\
\text { Bioinformatics }\end{array}$ & $\begin{array}{l}\text { - Quality Control (FastQC) } \\
\text { - Adaptor Trimming (TrimGalore) } \\
\text { - Alignment to in silico bisulfite converted BosTau8 genome } \\
\text { - Paired T-test (Young Vs. Old) at each CpG site }\end{array}$ \\
\hline Analysis of DMRs & $\begin{array}{l}\text { - Clustering Analysis of top } 100 \text { differentially methylated CpGs } \\
\text { - Functional Analysis (DAVID) } \\
\text { - Gene Expression (RT-qPCR) }\end{array}$ \\
\hline
\end{tabular}

Fig. 2 RRBS Project Workflow. Prior to methylation analysis, 6 pairs of fibroblasts isolated from the same animals at 5- and 16-months of age were selected and challenged with LPS for 0, 2, 8 and $36 \mathrm{~h}$ to measure cytokine protein and gene expression. In preparation for RRBS, fibroblast DNA was digested with MSPI to enrich for $\mathrm{CPG}$ rich regions of the genome, followed by end-repair and Poly-A tail addition. The digested DNA was then ligated to Illumina primers, size selected and bisulfite converted prior to sequencing. The subsequent reads were quality controlled by FastQC and Illumina adaptors were trimmed with TrimGalore. Those that passed quality control were then aligned to the BosTau8 genome and uniquely mapped reads were kept for analysis with a paired T test at each CpG site with greater than or equal to $5 \times$ coverage. Once differentially methylated sites were identified, clustering analysis was performed on the top 100 sites based on $p$-value. Functional analysis to identify enriched KEGG pathways, GO terms and transcription factors was performed by DAVID and gene expression analysis by RT-qPCR 
at each sequenced $\mathrm{CpG}$ site that met coverage requirements. Methylation analysis revealed 14,094 differentially methylated CpG sites with $P<0.05$ and at least $5 \times$ coverage. Of these, 9351 (67\%) were more methylated in young cultures and 4743 (33\%) were more methylated in old cultures. Clustering analysis was performed on the top 100 differentially methylated sites (i.e. sites with the greatest significant difference in methylation ratios). The old cultures and young cultures clustered separately, indicating that two distinct methylation profiles exist, where young cultures form one profile and old cultures form a second (Additional file 3).

\section{Suggestive analysis of differentially methylated genes}

Next, we performed a comprehensive, but suggestive functional analysis of all the sites that fell within gene regions and had $\geq 5 \times$ coverage. Of the 9351 sites more methylated in young cultures, 752 regions were located in annotated promoters, 720 in gene exons and 1926 in gene introns. Of the 4743 sites more methylated in old cultures, 365 were located in annotated promoters, 337 in gene exons and 965 in gene introns. Sites that fell within annotated genes were used to generate lists of gene IDs with greater methylation in either young or old cultures and functional analysis was performed using DAVID. KEGG pathway analysis on genes more methylated in young cultures identified 5 significantly enriched pathways. These included the "Adherens Junction", "Proteoglycans in Cancer", "Rap1 Signaling Pathway", "Pathways in cancer" and "Melanogenesis". It is worth noting that the "PI3K-Akt Signaling Pathway" was also enriched with $P=0.06$ after multiple comparisons correction. In older cultures, 16 pathways were significantly enriched, with the "Cholinergic Synapse" pathway as the top result. A number of secretory pathways and hormone synthesis pathways were also significantly enriched. Among the 16 pathways, those that were of most interest to the current study were the "Calcium Signaling Pathway", "Inflammatory mediator regulation of TRP channels" and "cAMP signaling pathway". Among the top significantly enriched GO terms in genes with greater methylation in young cultures were "Transcription Repressor Activity", "Sequence Specific DNA Binding", and "RNA Polymerase II regulatory region sequence-specific DNA binding". Interestingly, in older cultures, only one GO term, "Plasma Membrane" was significant and, in contrast to young cultures, lacked terms related to regulation of gene transcription.

Using the annotated genes from only the promoter sites with greater methylation in either young or old cultures, a transcription factor enrichment analysis was performed using DAVID and Homo sapiens as the background species, because Bos taurus is not yet supported in the UCSC_TFBS function. Table 2 shows the top 15
Table 2 Suggestive transcription factor enrichment of gene promoters more methylated in young cultures

\begin{tabular}{lllcl}
\hline Category & Term & Count $^{\mathrm{a}}$ & Fold enrichment $^{\mathrm{b}}$ & FDR $^{\mathrm{C}}$ \\
\hline UCSC_TFBS & PAX5 & 288 & 1.32 & $4.35 \mathrm{E}-09$ \\
UCSC_TFBS & LMO2COM & 297 & 1.31 & $6.04 \mathrm{E}-09$ \\
UCSC_TFBS & P53 & 321 & 1.25 & $2.23 \mathrm{E}-08$ \\
UCSC_TFBS & EGR3 & 111 & 1.77 & $5.34 \mathrm{E}-08$ \\
UCSC_TFBS & AP2 & 148 & 1.57 & $1.04 \mathrm{E}-07$ \\
UCSC_TFBS & NMYC & 174 & 1.48 & $1.57 \mathrm{E}-07$ \\
UCSC_TFBS & ARNT & 243 & 1.33 & $2.26 \mathrm{E}-07$ \\
UCSC_TFBS & NRSF & 265 & 1.29 & $3.42 \mathrm{E}-07$ \\
UCSC_TFBS & MYCMAX & 302 & 1.23 & $8.19 \mathrm{E}-07$ \\
UCSC_TFBS & NFKB & 246 & 1.30 & $1.43 \mathrm{E}-06$ \\
UCSC_TFBS & AHRARNT & 259 & 1.28 & $1.49 \mathrm{E}-06$ \\
UCSC_TFBS & CREB & 218 & 1.33 & $1.79 \mathrm{E}-06$ \\
UCSC_TFBS & E47 & 290 & 1.23 & $2.99 \mathrm{E}-06$ \\
UCSC_TFBS & COUP & 209 & 1.33 & $5.73 \mathrm{E}-06$ \\
UCSC_TFBS & TAXCREB & 262 & 1.25 & $6.31 \mathrm{E}-06$ \\
\hline
\end{tabular}

${ }^{\mathrm{a}}$ Number of inputted genes regulated by transcription factor listed

${ }^{b}$ Fold enrichment as measured by Fisher's Exact Test

'Benjamini-Hochberg False Discovery Rate

most significantly enriched transcription factors that regulate the inputted gene promoters more methylated in young cultures and Table 3 shows transcription factors enriched in gene promoters more methylated in old cultures. A number of transcription factors associated with immune system regulation and the inflammatory

Table 3 Suggestive transcription factor enrichment of gene promoters more methylated in old cultures

\begin{tabular}{lllcl}
\hline Category & Term & Count $^{\mathrm{a}}$ & Fold enrichment $^{\mathrm{b}}$ & FDR $^{\mathrm{C}}$ \\
\hline UCSC_TFBS & PAX5 & 187 & 1.43 & $8.40 \mathrm{E}-10$ \\
UCSC_TFBS & SP1 & 95 & 1.73 & $1.66 \mathrm{E}-06$ \\
UCSC_TFBS & ATF & 113 & 1.58 & $3.02 \mathrm{E}-06$ \\
UCSC_TFBS & NRSF & 165 & 1.35 & $9.59 \mathrm{E}-06$ \\
UCSC_TFBS & MIF1 & 136 & 1.43 & $1.06 \mathrm{E}-05$ \\
UCSC_TFBS & P300 & 124 & 1.47 & $1.09 \mathrm{E}-05$ \\
UCSC_TFBS & ZID & 150 & 1.38 & $1.14 \mathrm{E}-05$ \\
UCSC_TFBS & SREBP1 & 178 & 1.28 & $4.10 \mathrm{E}-05$ \\
UCSC_TFBS & MYOGNF1 & 145 & 1.35 & $6.27 \mathrm{E}-05$ \\
UCSC_TFBS & TAXCREB & 162 & 1.30 & $8.37 \mathrm{E}-05$ \\
UCSC_TFBS & ZIC3 & 123 & 1.41 & $8.80 \mathrm{E}-05$ \\
UCSC_TFBS & MZF1 & 147 & 1.33 & $9.46 \mathrm{E}-05$ \\
UCSC_TFBS & AHRARNT & 158 & 1.31 & $9.57 \mathrm{E}-05$ \\
UCSC_TFBS & HMX1 & 139 & 1.34 & $1.39 \mathrm{E}-04$ \\
UCSC_TFBS & TAL1BETAITF2 & 158 & 1.29 & $1.50 \mathrm{E}-04$ \\
\hline
\end{tabular}

${ }^{a}$ Number of inputted genes regulated by transcription factor listed

${ }^{b}$ Fold enrichment as measured by Fisher's Exact Test

'Benjamini-Hochberg False Discovery Rate 
response were associated with promoters more methylated in both young and old cultures. Most noteworthy in young cultures was greater methylation in NF- $\mathrm{kB}$ associated genes. Also, significantly more methylated in young cultures were genes regulated by PAX5 (also known as B-cell activating protein), and CREB (cAMP-regulated binding protein), a phosphorylation responsive transcription factor that binds to cAMP responsive elements.

In old cultures, PAX5 was similarly enriched along with SP.1, p300 (a CREB co-activator), and ATF or activating transcription factors, which are diverse members of the ATF/CREB family of transcription factors with a range of physiological functions.

\section{Conserved analysis of differentially methylated genes}

In a second, conserved analysis we focused solely on sites with $\geq 10 \times$ coverage, which is the minimum coverage that is necessary to accurately determine differentially methylated sites in an RRBS analysis. The additional filtering left 2865 differentially methylated sites. Of these, 1922 were more methylated in young cultures and 943 were more methylated in old cultures. In young cultures, 134 gene promoters, 98 exons and 354 introns were hyper-methylated and in old cultures only 42 gene promoters, 45 exons and 150 introns were hyper-methylated in comparison to young cultures. The genes associated with these regions were used to conduct a conserved GO, KEGG and TFBS analysis. Interestingly, with the additional filtering we found no significant GO terms associated with either young or old cultures, although "Semaphorin Receptor Activity" trended $(P<0.10)$ towards significance in old cultures. Two KEGG pathways, "Adherens Junction" and "Proteoglycans in Cancer" remained significantly associated with young cultures and no KEGG pathways were found to be associated with old cultures. Finally, 21 transcription factors were identified as significantly enriched in hypermethylated promoter regions in young cultures, the top 10 of which are listed in Table 4. We did not identify any transcription factors enriched in our assessment of hyper-methylated promoters in old cultures. Many of the transcription factors that were identified in the suggestive analysis in young cultures remained significant, including PAX5 and most notably, NF- $\mathrm{kB}$ that was found to be associated with 56 out of 134 gene promoters more methylated in young cultures.

\section{Fibroblast gene expression of differentially methylated genes}

Selected differentially methylated genes were analyzed by RT-qPCR to determine whether changes in methylation resulted in differences in gene expression. The rationale for choosing the analyzed genes was that there was a greater than $25 \%$ methylation difference in at least
Table 4 Conserved transcription factor enrichment of gene promoters more methylated in young cultures

\begin{tabular}{lllcl}
\hline Category & Term & Count $^{\mathrm{a}}$ & Fold enrichment $^{\mathrm{b}}$ & FDR $^{\mathrm{C}}$ \\
\hline UCSC_TFBS & P300 & 49 & 1.67 & 0.007 \\
UCSC_TFBS & TAL1BETAITF2 & 60 & 1.40 & 0.024 \\
UCSC_TFBS & CDC5 & 52 & 1.46 & 0.027 \\
UCSC_TFBS & ROAZ & 52 & 1.44 & 0.027 \\
UCSC_TFBS & P53 & 69 & 1.29 & 0.028 \\
UCSC_TFBS & COUP & 48 & 1.46 & 0.031 \\
UCSC_TFBS & NFKB & 56 & 1.42 & 0.032 \\
UCSC_TFBS & EGR3 & 25 & 1.92 & 0.032 \\
UCSC_TFBS & AP2 & 35 & 1.78 & 0.032 \\
UCSC_TFBS & AP2GAMMA & 18 & 2.19 & 0.040 \\
\hline
\end{tabular}

${ }^{a}$ Number of inputted genes regulated by transcription factor listed

${ }^{\mathrm{b}}$ Fold enrichment as measured by Fisher's Exact Test

'Benjamini-Hochberg False Discovery Rate

one region in young versus old cultures, the sites had on average greater than $10 \times$ coverage across the 12 animals, methylation was greater in young versus old cultures and that there was some evidence in the literature that the genes are involved in immune response regulation. The six selected genes, and number and location of differentially methylated regions are listed in Table 5, along with a summary of expression differences.

Gene expression analysis of the LPS responsiveness of the six selected genes hyper-methylated in young versus old cultures is shown in Fig. 3. Overall, 5 of the 6 selected genes showed a reduced expression in cultures established from the animals at 5 vs. 16 months of age. Two of the 6 genes, FES and PIK3R1, had reduced expression in the younger cultures at all 3 time points, with a 5.7, 4.3 and 6.3-fold $(P<0.01)$ lower expression in FES and 3.0, 2.6, and 2.5-fold $(P<0.01)$ lower expression in PIK3R1 at 0,2 and $8 \mathrm{~h}$ post LPS stimulation, respectively. Both genes had differentially methylated sites located in the promoter region, a single site located 23 base pairs upstream from the transcription start site (TSS) of PIK3R1 and two sites, 4 and 6 base pairs, downstream of the TSS in FES. Additionally, FES had two differentially methylated sites located within exon regions and PIK3R1 had one site located within the first intron of the gene. Expression of these genes was not affected by LPS stimulation.

A gene that encodes a TNF superfamily member ligand, TNFSF13 also known as APRIL, also showed significantly lower expression in young cultures at 0 and $8 \mathrm{~h}$ post LPS stimulation ( 2.0 and 2.8 -fold, $P<0.05$ ), with a trend towards significantly lower expression at $2 \mathrm{~h}$ (1.6-fold, $P<0.10$ ), but was not affected by LPS stimulation. TNFSF13 had one differentially methylated site in the gene promoter region, 145 bases upstream from the TSS in the anti-sense position and directly downstream 
Table 5 Summary of selected innate response genes hyper-methylated in young cultures

\begin{tabular}{lllll}
\hline Gene name & $\begin{array}{l}\text { Number of differentially } \\
\text { methylated sites }^{a}\end{array}$ & $\begin{array}{l}\text { Location of differentially } \\
\text { methylated sites }\end{array}$ & $\begin{array}{l}\text { Expression (Old }>\text { Young) } \\
\text { at 0, 2 \& 8 H post LPS }\end{array}$ & $\begin{array}{l}\text { Expression (Holstein }>\text { Angus) } \\
\text { at 0, 2, \& 8 H post LPS }\end{array}$ \\
\hline FES & 2 & Promoter, Exon & $5.7,4.3,6.3$ & $3.7,5.4,4.8$ \\
NFATC1 & 3 & Promoter, Intron & $1.8,1.8,-$ & $2.2,6.5,1.7$ \\
PIK3R1 & 2 & Promoter, Intron & $3.0,2.6,2.5$ & $-, 2.4,(-1.9)$ \\
RORA & 5 & Intron &,,-- 2.1 & $2.0,2.2,-$ \\
TNFSF13 & 1 & Promoter & $2.0,1.6,2.8$ &,,--- \\
TCF7 & 2 & Promoter &,,--- & $4.5,-, 4.3$
\end{tabular}

${ }^{\mathrm{a}}$ Number of differentially methylated $\mathrm{CpGs}(P<0.05,>25 \%$ meth diff $)$

${ }^{b}$ Displayed as fold change at 0,2 or $8 \mathrm{H}$ post LPS. Positive values indicate (Old $>$ Young) or (Holstein $>$ Angus), negative values indicate (Young $>$ Old) or (Angus $>$ Holstein) and - signifies $P>0.10$

from a site on the positive strand with $93 \%$ sequence similarity to the consensus NF-kB binding site. The gene, NFATC1, that encodes an LPS responsive transcription factor, had significantly lower expression in young versus old cultures at 0 and $2 \mathrm{~h}$ post LPS stimulation, with both time points showing a 1.8 -fold $(P<0.05)$ lower expression in young cultures. Expression of NFATc1 also increased $17.5+/-5.6$-fold $2 \mathrm{~h}$ post LPS stimulation, with no difference in fold change between young and old cultures. By $8 \mathrm{~h}$ post-challenge, expression returned to near basal levels. The NFATC1 gene had one differentially methylated site located within a
CpG island in the promoter region, approximately 1000 bp upstream from the TSS and downstream of a potential Sp1 binding site. Two additional differentially methylated sites were located within the last intron of the NFATC1 gene.

The only selected gene that did not have differences in promoter methylation, $R O R A$, had 6 differentially methylated sites located in the first intron of the gene. Gene expression analysis showed significantly lower levels of expression in young versus old cultures at $8 \mathrm{~h}$ post LPS treatment $(2.1$-fold, $P<0.001)$ with no change in response to LPS. Finally, we measured TCF7, the gene

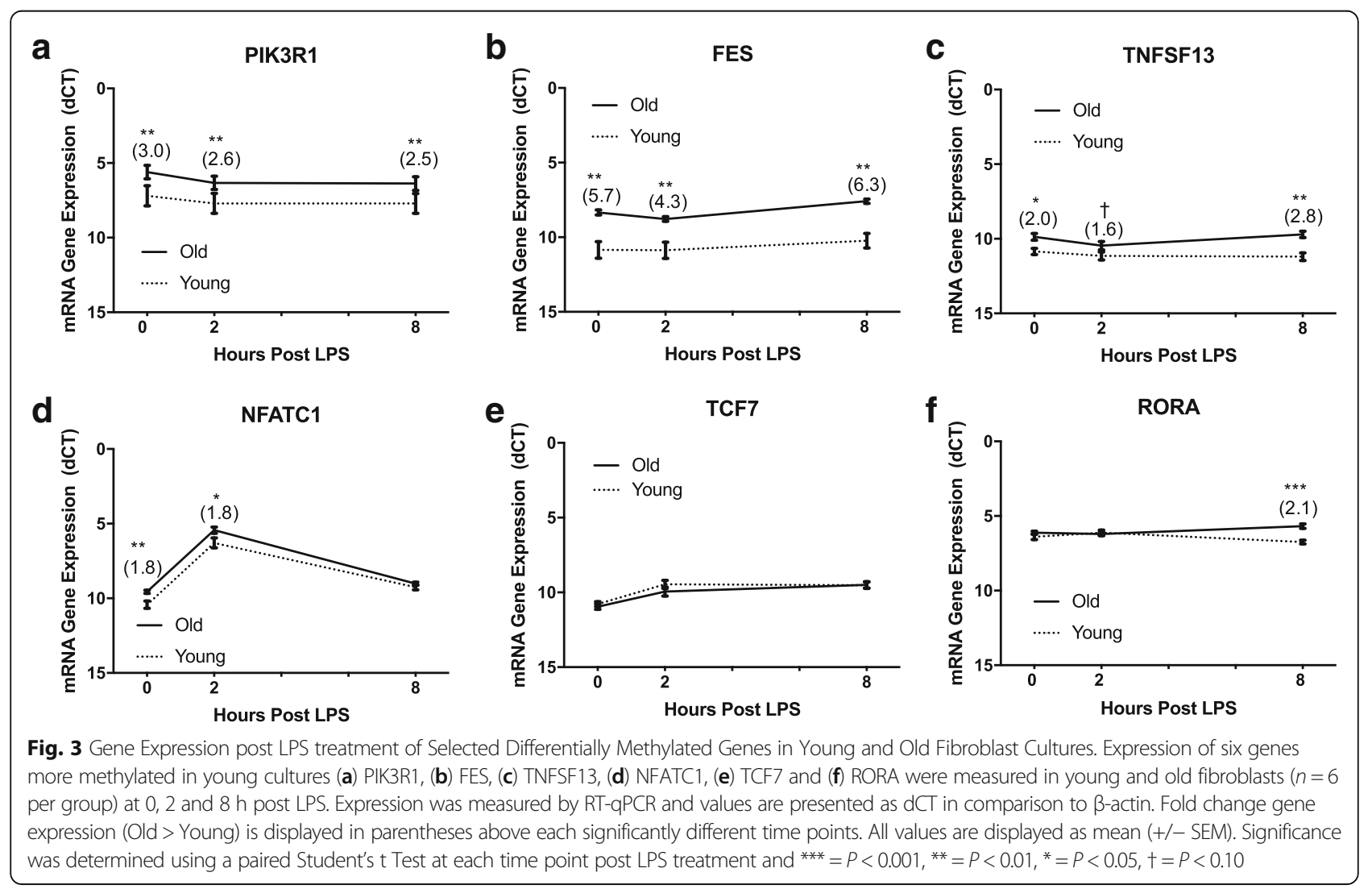


that transcribes the transcription factor TCF7, that had 2 differentially methylated sites located within a CpG island in the promoter region. The first $\mathrm{CpG}$ was located approximately $1200 \mathrm{bp}$ upstream from the TSS and near to a potential NFAT5 binding site and the second CpG was approximately 979 bp upstream from the TSS on the anti-sense strand. Interestingly, no significant expression differences were detected in young versus old cultures. However, there was a small increase in gene expression of TCF7 in response to LPS. Expression was increased $2.3+/-0.7$-fold and $2.7+/-0.9$-fold at 2 and $8 \mathrm{~h}$, respectively, with no difference between young and old cultures.

\section{Gene expression of differentially methylated genes in Angus vs. Holstein fibroblast cultures}

Finally, we wanted to determine whether differentially methylated genes identified in young versus old cultures would differ in expression in a second high vs. low LPS responsive cattle phenotype recently discovered in our laboratory. Just as with the age difference, we have shown that dermal fibroblasts collected from the Holstein breed are much more responsive to LPS than fibroblasts collected from the Angus breed [26]. To determine whether similar gene expression differences could be detected between breeds, RT-qPCR was performed on age-matched dermal fibroblast cultures at 0 , 2 and $8 \mathrm{~h}$ post-LPS treatment. Greater LPS-induced IL-8 and IL- 6 protein production and gene expression in Holstein vs. Angus cultures have been described elsewhere [26].

Gene expression analysis was performed on the same 6 genes that were differentially methylated in the young versus old fibroblast cultures, where young cultures had greater methylation and, with the exception of TCF7, lower expression. As shown in Fig. 4 and summarized in Table 5, the majority of the genes were similarly upregulated in Holstein cultures as they were in older cultures. Two notable exceptions to the pattern seen in our young versus old analysis were in TNFSF13, where no difference was measured in Angus versus Holstein cultures, and in TCF7 which was upregulated in Holstein cultures at 0 and $8 \mathrm{~h}$ post LPS treatment. Under basal conditions, Holstein cultures expressed TCF7 4.5 -fold $(P<0.01)$ higher than Angus cultures and at $8 \mathrm{~h}$ post LPS TCF7 expression was 4.3-fold $(P<0.05)$ higher in Holstein cultures. Interestingly, at $2 \mathrm{~h}$ post LPS treatment, Angus cultures increased TCF7 gene expression 5-fold, while Holstein cultures only increased expression 2-fold. This fold increase at $2 \mathrm{~h}$ was significantly higher in Angus

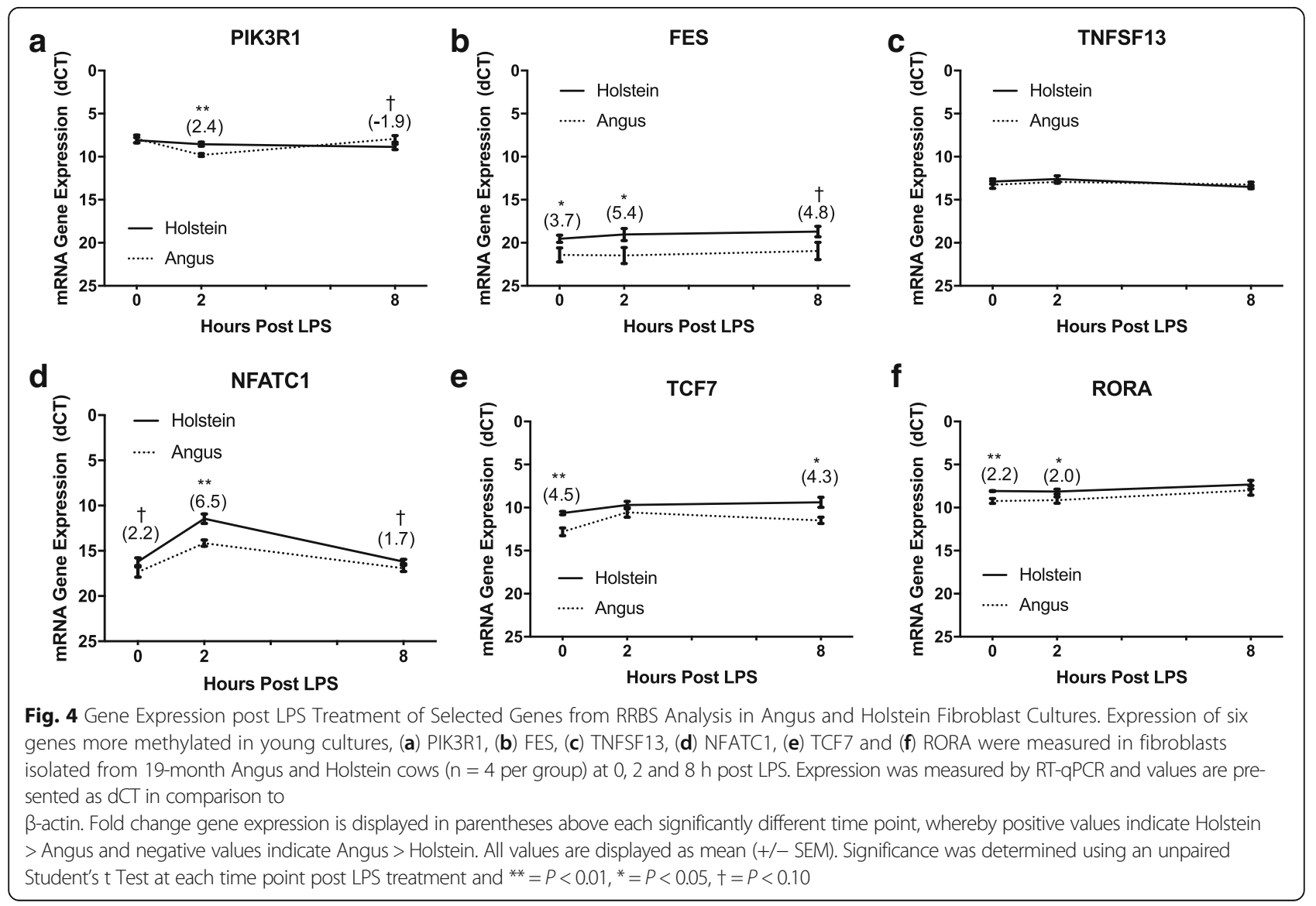


cultures $(P<0.05)$ as compared to Holstein cultures, although Holstein cultures did have a significantly $(P<$ 0.05 ) higher level of expression at 2 versus $0 \mathrm{~h}$. While Holstein cultures continued to maintain elevated expression of TCF7, Angus cultures had started to return to basal levels of expression at $8 \mathrm{~h}$ post LPS, although expression was still significantly higher $(P<0.05)$ than without treatment.

Similar to old cultures, Holstein cultures had significantly $(P<0.05)$ higher expression of FES at 0 and $2 \mathrm{~h}$ post LPS treatment, with expression levels being 3.7 and 5.4-fold higher, respectively, and a trend (4.8-fold, $P<0.10$ ) towards higher expression in Holstein cultures at $8 \mathrm{~h}$ post LPS. PIK3R1 also had higher levels of expression $(P<0.01)$ $2 \mathrm{~h}$ post-LPS treatment in Holstein cultures. This difference was due to a significant $(P<0.01)$ 4-fold decrease in PIK3R1 gene expression in Angus cultures that was not detected in Holstein cultures. By $8 \mathrm{~h}$ post LPS treatment, PIK3R1 expression returned to near-basal levels in Angus cultures.

Most noteworthy was the gene, NFATC1, which showed a very similar gene expression pattern between breeds as was seen in the age difference. Both Angus and Holstein cultures significantly increased their expression of NFATc1 at $2 \mathrm{~h}$ post LPS treatment (30-fold and 12-fold respectively), with Holstein cultures having a 6.5-fold higher $(P<0.01)$ level of expression over Angus cultures at $2 \mathrm{~h}$ post LPS. Holstein cultures also trended towards greater expression (2.2 and 1.7-fold, $P$ $<0.10)$ at 0 and $8 \mathrm{~h}$ post-LPS. By $8 \mathrm{~h}$ post LPS, both breeds returned to basal levels of expression. Finally, RORA, had higher $(P<0.01)$ levels of expression in Holstein cultures at 0 and $2 \mathrm{~h}$ post LPS treatment. At $0 \mathrm{~h}$, Holstein cultures had a 2.2-fold higher level of expression and at $2 \mathrm{~h}$ they had a 2.0-fold higher level of expression. No LPS treatment effect was detected.

\section{Discussion}

An increase in the systemic production of proinflammatory mediators has been well characterized as a component of the aging process, heightening the risk of cardiovascular, neurodegenerative and other diseases in humans. This process, coined by Franceschi et al.,[34] as "inflamm-aging", is highlighted by increased concentrations of serum TNF- $\alpha$, IL1- $\beta$ and IL- 6 along with acute phase proteins, such as $C$ reactive protein $[34,35]$. To determine the potential mechanism behind an increase in chronic inflammation associated with age, both in healthy aging individuals and during the diseased state, regulation of pro-inflammatory gene expression by DNA methylation has been widely studied.

A substantial decrease in methylation at a single CpG site in the promoter of the IL6 gene was measured in patients with rheumatoid arthritis versus healthy controls. In the same study, ranking of healthy control macrophages in response to LPS showed that an increase in LPS-induced IL-6 production was correlated with a decrease in IL6 promoter methylation [36]. Epigenetic regulation of another pleiotropic proinflammatory cytokine gene, TNF, has been similarly described. In comparison to healthy controls, patients with previous exposure to the Dengue virus have higher blood TNF- $\alpha$ expression with a concomitant decrease in promoter methylation [37]. DNA methylation changes have also been reported to occur in TNF in humans as part of the natural aging process. Macrophages obtained from 78 healthy individuals showed a $1.4 \%$ per decade decrease in three 5 ' CpG motifs located with the TNF promoter [38]. Increased methylation of TLR4, the key TLR in response to LPS, has also been shown in the context of intestinal epithelial homeostasis, whereby intestinal epithelial cells are made tolerant to stimulation by commensal microbiota through down-regulation of TLR4 to avoid continuous inflammation [39]. In that study, a comparison between a high responding and a low responding intestinal epithelial cell line showed that the lower responding cells not only exhibit decreased expression but also enhanced methylation in $11 \mathrm{CpG}$ sites in the gene promoter of the TLR4 gene. Furthermore, inhibition of DNA methylation with AZA treatment in these two cell lines abolished the difference in TLR4 expression, further establishing a causal role for DNA methylation in the regulation of TLR4 [39].

Research on epigenetic regulation of the immune response in livestock species has been somewhat more limited. However, it has been shown that in response to LPS treatment, bovine PBMCs decrease expression of methylation and histone deacetylation enzymes, suggesting LPS treatment may result in lower gene methylation and increased histone acetylation [40]. The effects of Mycobacterium bovis infection on global DNA methylation and gene expression have also been reported in bovine CD4+ T- cells, whereby, DNA methylation was negatively correlated with expression of interferon- $\gamma$ (IFNG) and a gene that encodes the OX-40 receptor (TNFRSF4). The two genes, IFNG and TNFRSF4, are involved in $\mathrm{T}$-cell response and proliferation, respectively, and provide one potential mechanism that contributes to the shift from Th1 to Th2 T-cell response following bovine tuberculosis infection [41]. Epigenetic mechanisms have also been shown to play a role in the hepatic expression of TLR4, lipopolysaccharide binding protein (LBP) and haptoglobin in response to E. coli mastitis. Chromatin de-compaction and increased expression of key innate response genes, LBP, HP, TLR2 and TLR4 occurs in liver biopsies following an intra-mammary challenge with E. coli. In TLR4, the chromatin changes are also correlated with promoter de-methylation [42]. In a similar study that assessed the effects of feeding a 
high concentrate diet to induce sub-acute ruminal acidosis (SARA), chromatin de-compaction and expression of these innate response genes was again increased in liver biopsies with subsequent DNA de-methylation seen in all four genes. Presumably, these changes were a result of greater concentrations of LPS found in the rumen, and hepatic and portal veins of cows experiencing SARA [43].

To elucidate the underlying causes of differences in innate response to mastitis causing pathogens, we have taken advantage of two phenotypes with clear response differences, age and breed, where fibroblasts from older versus younger animals [22], and Holstein versus Angus animals [26] have much higher in vitro responses. The age-dependent difference in response has also been shown to be at least partially mediated by epigenetic mechanisms. Inhibition of DNA methylation and histone deacetylation in fibroblasts isolated from the same animal at 5- and 16-months of age abolishes differences in in vitro cytokine production suggesting methylation, chromatin modifications, or both contribute to the agedependent increase in response [21]. To determine which genes are regulated by DNA methylation, methylated CpG island recovery assay or MIRA-seq, was previously performed on both the age and breed phenotypes following RNA-seq analysis. Unfortunately, this technique, which utilizes the protein complex MBD2bMBD3L1 complex to enrich for methylated regions within the genome, has only moderate resolution ( $500 \mathrm{bp})$ and few differences were detected in both phenotypes that fell within gene regions and none of these differences were detected in regions with a role in the innate response. Since it is known that small changes in methylation can be effective in changing gene expression it was necessary to utilize a more sensitive technique, such as was performed in the current study.

\section{Methylation differences in 5- versus 16-month dermal fibroblasts}

Reduced representation bisulfite sequencing was performed on fibroblasts taken from 5- and 16-month old heifers that had significantly different IL-8 and IL-6 protein production and gene expression. This analysis revealed 14,094 differentially methylated CpG sites. Approximately two-thirds of these sites were more methylated in younger cultures, consistent with previous data suggesting global hypo-methylation in older individuals $[44,45]$. The transcription factor, NF- $\mathrm{kB}$ which is a major activator of pro-inflammatory gene expression downstream of a number of pattern recognition receptors and TNF-associated receptors [46], was identified as significantly associated with hyper-methylated promoter regions in young cultures. This suggests that increased methylation in young cultures may block NF- $\mathrm{kB}$ binding sites, reducing transcription of pro-inflammatory genes. Blocking of NF- $\kappa B$ gene transcription by DNA methylation has been shown to occur in patients with secondary acute myeloid leukemia (sAML), where hematopoietic progenitor cells fail to express Fas receptor, an activator of apoptosis. The $F A S$ gene was shown to contain $3 \mathrm{ca}-$ nonical NF- $\mathrm{kB}$ binding sites and increased methylation in bone marrow blast cells from patients with sAML as compared to those with low-risk myelodysplastic syndrome whose Fas expression remains intact. In addition, re-expression of Fas occurred in sAML patients upon de-methylation with AZA [47]. Although only identified in our suggestive ( $\geq 5 \times$ coverage) analysis, the transcription factor, cAMP regulated binding protein (CREB), was also associated with gene promoters more methylated in young cultures. Downstream of a wide variety of serine-threonine kinases (such as PKA, PKC, and p38 MAPK) CREB regulates a multitude of processes, including the innate immune response [48]. Recently, CREB has been shown to mediate TNF- $\alpha$ dependent GM-CSF production in primary asthmatic lung fibroblasts and human fetal lung fibroblasts [49]. CREB also increases LPS and TLR4 dependent IL-6 production in vascular smooth muscle cells which may contribute to the vascular inflammation seen in atherosclerosis [50].

In older cultures, transcription factor binding sites for Sp1, p300 and ATF, were enriched in hyper-methylated genes. Numerous genes contain $\mathrm{Sp} 1$ binding sites, which are located in GC-rich regions often regulated by DNA methylation. Somewhat contradictory to our hypothesis, Sp1 does up-regulate expression of some innate response genes. In intestinal epithelial cells, basal expression of TLR5 is regulated by Sp1. Interestingly, inducible expression of TLR 5 is also partially mediated by p300, in agreement with our results that both Sp1 and p300 regulated genes were hyper-methylated in older cultures [51]. Alternatively, in response to LPS, Sp1 enhances macrophage transcription of IL-10, a key anti-inflammatory cytokine [52]. ATFs are members of the activating transcription factor/cAMP responsive element binding protein (ATF/CREB) family of transcription factors. It was not clear with DAVID analysis which of the family members were enriched in regulation of the genes more methylated in older cultures, however, analysis of just the 106 genes regulated by ATF showed that 62 were regulated by ATF6. ATF6 is a key transcription factor that is activated under ER stress and mediates the unfolded protein response. Again, contrary to our data, ER stress contributes to inflammation during an infection with Brucella abortis in a NOD1/NOD2 dependent manner and the unfolded protein response has been shown to strengthen NF- $\mathrm{kB}$ dependent inflammation $[53,54]$. However, other ATFs, such as ATF3 have been shown to have the opposite effect and reduce 
inflammatory gene expression [55]. Furthermore, when additional stringency was applied to the TFBS analysis to include only genes that contained differentially methylated sites with $\geq 10 \times$ coverage we failed to identify any transcription factors associated with genes hypermethylated in old cultures, unlike what was found in young cultures. An additional caveat to the transcription factor binding data used in the current study is that conclusions were drawn on sequence conservation found between human and rodent alignments. Sequence conservation does not necessarily result in transcription factor binding and regulation and whether enrichment of the identified transcription factors regulate cellular response differences to LPS in a methylation-dependent manner would need to be validated in our model.

\section{Gene expression analysis of differentially methylated genes}

Methylation of DNA is most known for its role in repressing gene transcription. To determine if the measured methylation differences had any effect on gene expression, we chose six genes that exhibited higher methylation in young cultures for RT-qPCR analysis. We hypothesized these six genes would have lower expression in the young cultures due to their increased methylation status. We chose the following six genes for their potential role in the innate response: TNFSF13, PIK3R1, NFATC1, FES, TCF7 and RORA. The TNF superfamily 13 , or APRIL, protein is a surface or secreted ligand recognized by the transmembrane activator and calciummodulating cyclophilin ligand interactor (TACI) and Bcell maturation antigen (BCMA) receptors and has been implicated in the pathogenesis of numerous proinflammatory conditions such as rheumatoid arthritis [56], atherosclerosis [57], lupus [58] and psioriasis [59]. Moreover, APRIL has been shown to activate NF- $\mathrm{BB}$ dependent cytokine production in macrophages [60] and keratinocytes [59]. In our analysis, fibroblast expression was significantly up-regulated in older cultures at 0 and $8 \mathrm{~h}$ post LPS treatment as we expected. The single site hyper-methylated in young cultures was located near to the consensus NF- $\mathrm{kB}$ binding sequence, 5'-GGGRNYY YCC-3'. However, since the gene did not increase after LPS treatment and was already up-regulated under basal conditions, it is unlikely NF- $\mathrm{KB}$ regulates its transcription in response to LPS.

The gene, PIK3R1, transcribes the p85 $\alpha$ subunit of phosphoinositide 3-kinase (PI3K), a lipid kinase that phosphorylates phosphatidylinositol 4,5-bisphosphate (PIP2) to phosphatidylinositol 3,4,5-trisphosphate (PIP3). The $\mathrm{p} 85 \alpha$ subunit is a regulator of kinase activity, whereby it is thought to inhibit PI3K activity under most circumstances [61]. Interestingly, in a murine model of polymicrobial sepsis, inhibition of the PI3K pathway increased serum IL1- $\beta$, IL- 6 and TNF- $\alpha$ levels and decreased the survival rate of septic mice [62]. Alternatively, pharmacological activators of PI3K signaling have recently been suggested as anti-inflammatory drug candidates [63]. However, the role of PI3K in inflammation is complex, since kinase activity can also activate leukocytes and is further complicated by the existence of multiple isoforms of PI3K with a variety of physiological functions [64]. In our model, PIK3R1 expression was up-regulated in older cultures at all 3 time points post LPS with a fairly consistent fold change of $2.5-3.0$ fold. A single CpG site in the promoter region was more highly methylated, only 23 base pairs from start site of the gene, potentially interfering with the progression of the RNA polymerase enzyme complex.

Nuclear factor of activated T-cells, calcineurin dependent 1 (NFATc1), the gene product of NFATC1, is a calcium dependent transcription factor that is necessary for lymphocyte development and is expressed in a number of other cell types such as dendritic cells [65], macrophages [66] and endothelial cells [67] and is responsible for mediating TLR-4 independent, CD-14 dependent pro-inflammatory gene expression in response to microbial agonists, such as LPS. Interestingly, the NFATC1 gene is less methylated and more expressed in individuals with lower socioeconomic status which is a known risk factor for increased inflammation that can lead to pathologies such as type II diabetes $[68,69]$. In our study, NFATc1 was induced following LPS stimulation in both young and old fibroblasts, further solidifying its role as an LPS-responsive transcription factor. In the promoter, the differentially methylated $\mathrm{CpG}$ was located directly downstream of a $\mathrm{Sp} 1$ binding site that has been shown in numerous recent studies to bind at lower levels with increased DNA methylation status [70-72]. In addition, two other sites were located in the last intron of the gene. This is of interest because an enhancer element has been identified using human lymphocytes within the last intron of the NFATc1 gene that activates transcription to an even greater extent than the promoter region of the gene [73].

Feline sarcoma oncogene (FES) is a non-receptor tyrosine kinase that, in humans, stimulates hematopoiesis, osteoclastogenesis and mast cell activation [74]. It is worth mentioning that both FES and PI3-K activate mast cells through a similar SCF-c-Kit-integrin pathway and the two proteins have been speculated to interact with one another through tyrosine phosphorylation of PI3-K by FES [75, 76]. As with PIK3R1, FES kinase expression was also similarly up-regulated at all time points in older cultures while younger cultures had two hyper-methylated sites near to the transcriptional start site which again may interfere with transcriptional elongation by RNA polymerase. 
Transcription factor 7 (TCF7), transcribed from the gene TCF7 is a transcription factor that is crucial to the proper development of T-cells in the thymus, but has been shown to inhibit the development of regulatory $\mathrm{T}$ cells, or Tregs, which suppress inflammation and aid in the resolution of infection [77]. Although several methylation differences were detected within the promoter region of TCF7, no difference in expression was measured in fibroblasts either basally or post LPS. There are a couple of possible explanations for this discrepancy. Methylation itself may not be sufficient to repress expression and it is likely an over-simplification to assume methylation always leads to repression. For example, in a study assessing the relationship between methylation and gene transcription in the blood of 148 healthy human subjects, the authors found that 276 of 798 local associations were actually positively associated, where less methylation led to less transcription or more methylation led to more transcription [78]. Other factors, such as histone modifications and transcription factors that also have an effect on transcription should be taken into consideration as they can override any differences in methylation as has been shown in the differentially imprinted gene $I G F 2 R$ [79]. Lastly, it is possible that splice variants of TCF7 exist that exhibit differential expression in our samples but were not measured in our RT-qPCR analysis.

Finally, RORA, or retinoic acid related (RAR) orphan receptor alpha, belongs to a family of nuclear receptor transcription factors (RORs) which have known roles in the innate and adaptive immune response, circadian rhythm and metabolic regulation, among others [80]. Specifically, RORA is required for the development of type II innate lymphoid cells and mice lacking the gene experience reduced eosinophil-mediated lung inflammation in response to allergens [81] and are less susceptible to obesity induced inflammation in response to a high fat diet [82]. We detected a small, but significant increase in RORA expression in older fibroblasts at 8-h post LPS. In this case, we identified 6 methylation differences all within first intron of the gene which can contain enhancer elements for gene activation [83].

\section{Expression of differentially methylated genes in Angus versus Holstein fibroblasts}

In our final experiment, we wanted to determine whether similar expression differences could be detected in another high-low response phenotype, a breed difference identified in our lab that shows the Holstein breed having a much higher in vitro response as compared to the Angus breed [26]. Genes similarly up-regulated in Holsteins might suggest a conserved mechanism of regulation, such as DNA methylation or other epigenetic modifications. This of particular interest in the breed difference as these two breeds are not only genetically selected for divergent purposes but also experience highly dissimilar neonatal environments, leaving room for possible environmental interventions. Many studies have shown that neonatal nutrition, maternal care and exposure to immune agonists can shape an individual's adult epi-genotype and all three of these environmental influences differ between Holstein and Angus calves. Angus calves are maternally cared for in a pasture setting, drink milk from their dam, and are exposed to a variety maternally-derived commensal and environmental microbes in contrast to Holstein calves that are raised individually without maternal contact, fed milk replacer, and are housed in a considerably more defined environment.

Expression analysis of fibroblasts isolated from the two breeds showed some similar differences to our agedependent differences. In the high responding Holstein breed, FES, NFATC1, RORA, and to a lesser extent PIK3R1, were up-regulated. Additionally, TCF7 was upregulated, a difference not detected in the young-old culture comparison. This discrepancy may indicate a genetic difference as a result of selection for different traits (beef versus dairy) between Angus and Holstein breeds. No difference was measured in TNFSF13 suggesting the loss of methylation is unique to the aging process. Most noteworthy of the differentially expressed genes were FES and NFATC1. These two genes showed an identical pattern of up-regulation in Holstein cells as was seen in older cells, indicating they may be similarly regulated. However, additional experiments with the Holstein and Angus cultures would be necessary to confirm whether expression differences are due to differences in methylation or other epigenetic factors, genetic differences, or a combination of factors. Expression of FES is upregulated basally in both high response phenotypes, making it a candidate biomarker for selection strategies which would require a rapid test without the need of culturing cells and treating with LPS. Additionally, NFATC1 is of interest due to its role in the response to LPS and as a known contributor to many proinflammatory pathologies. Future studies assessing methylation differences in Angus and Holstein breeds are underway and should provide insight into how this phenotype is regulated.

One limitation of the current study was that the RRBS technique does not allow for a comprehensive methylation analysis and as a result many CpG sites are missed. This may be one reason why we failed to identify methylation differences in classic LPS response genes that show similar up-regulation of expression in both high responding phenotypes. Targeted bisulfite sequencing of candidate genes, such as TLR4 and IL8, will be the subject of future experiments to determine whether 
methylation may influence expression of genes that directly mediate LPS response.

\section{Conclusions}

Overall, the current study has shown that many sites differ in their methylation status in young versus old cultures, with the majority of sites becoming less methylated as the animals increased in age. Candidate innate response genes that were hyper-methylated in young cultures also exhibited lower expression in most instances, indicating methylation may suppress expression in younger cultures making them less responsive to TLR agonists, such as LPS. Expression analysis in a second high-low response phenotype, Angus versus Holstein fibroblasts, identified two genes (FES and NFATC1) that showed an identical response pattern as the young and old cultures. These two genes may be useful as candidate biomarkers for predicting whether an animal will have a high or low response phenotype, and subsequently, whether she is susceptible to severe mastitis. In conclusion, knowledge of critical changes in methylation that increases the magnitude of inflammatory response within an individual may elude to the mechanisms of between-individual variation in the innate response. This is particularly important in diseases where an unregulated innate response contributes to the pathology of the disease, such is the case in bovine mastitis.

\section{Additional files}

Additional file 1: Hyper-methylated genes in 5-month cultures. Table S1. Hyper-methylated promoter regions. Table S2. Hyper-methylated exon regions. Table S3. Hyper-methylated intron regions. (XLSX 209 kb)

Additional file 2: Hyper-methylated genes in 16-month cultures. Table S1. Hyper-methylated promoter regions. Table S2. Hyper-methylated exon regions. Table S3. Hyper-methylated intron regions. (XLSX $129 \mathrm{~kb}$ )

Additional file 3: Clustering analysis on the top 100 differentially methylated sites in young $(1 \mathrm{~A}-6 \mathrm{~A})$ versus old cultures (1B - 6B). (PDF $276 \mathrm{~kb}$ )

\footnotetext{
Abbreviations

ATF: Activating transcription factor; AZA-TSA: 5-aza-2-deoxycytidine and Trichostatin A; CREB: CAMP regulated binding protein; DAVID: Database for Annotation, Visualization, and Integrated Discovery; DMC: Differentially methylated CpG; DMR: Differentially methylated region; E. coli: Escherichia coli; FES: Feline sarcoma oncogene; GO: Gene Ontology; IL-6: Interleukin-6; IL8: Interleukin-8; KEGG: Kyoto Encyclopedia for Genes and Genomes; LPS: Lipopolysaccharide; MIRA: Methylated CpG island recovery assay; Mr: Methylation ratio; NFATc1: Nuclear factor of activated T-cells, calcineurin dependent 1; PAMP: Pathogen associated molecular pattern; PI3K: Phosphoinositide 3-kinase; PIK3R1: Phosphatidylinositol 3-kinase regulatory subunit alpha; PRR: Pattern recognition receptor; RORA: Retinoic acid related orphan receptor alpha; S. aureus: Staphylococcus aureus; SAML: Secondary acute myeloid leukemia; SARA: Sub-acute ruminal acidosis; TCF7: Transcription factor 7; TFBS: Transcription factor binding site; TLR: Tolllike receptor; TNFSF13: Tumor Necrosis Factor Super Family 13;

TSS: Transcription start site; WGBS: Whole genome bisulfite sequencing
}

\section{Acknowledgements}

The authors would like to thank Keith Booher, Hunter Chung and Karolyn Giang at Zymo Research for technical assistance with post-sequencing analysis.

\section{Funding}

This work was supported by the National Institute of Food and Agriculture/ United States Department of Agriculture under Grant\# VT-0076CG. The funding agency did not have a role in study design, data collection and analysis or in writing the manuscript.

\section{Availability of data and materials}

The raw data sets used to support the conclusions of this article are available on NCBI's Gene Expression Omnibus (GEO) through GEO accession number GSE91088. http://www.ncbi.nlm.nih.gov/geo/query/acc.cgi?acc=GSE91088

\section{Authors' contributions}

FK and DK were responsible for the conception and design of the experiment. FK performed all experiments, analyses and manuscript preparation. DK was the principal investigator for the study and provided edits for the final manuscript. Both authors have read and approved the final version.

\section{Competing interests}

The authors declare that they have no competing interests.

\section{Consent for publication}

Not applicable.

\section{Ethics approval and consent to participate}

This study was approved by the Institutional Animal Care and Use Committee at the University of Vermont (UVM). All animals came from a research and teaching herd owned by UVM and housed at the UVM Miller Research farm in Burlington, VT.

\section{Publisher's Note}

Springer Nature remains neutral with regard to jurisdictional claims in published maps and institutional affiliations.

Received: 9 December 2016 Accepted: 16 May 2017 Published online: 25 May 2017

\section{References}

1. Michel T, Reichhart JM, Hoffmann JA, Royet J. Drosophila Toll is activated by Gram-positive bacteria through a circulating peptidoglycan recognition protein. Nature. 2001;414(6865):756-9.

2. Lemaitre B, Nicolas E, Michaut L, Reichhart JM, Hoffmann JA. The dorsoventral regulatory gene cassette spatzle/Toll/cactus controls the potent antifungal response in Drosophila adults. Cell. 1996;86(6):973-83.

3. De Nardo D. Toll-like receptors: Activation, signalling and transcriptional modulation. Cytokine. 2015;74(2):181-9.

4. Uchiyama R, Chassaing B, Zhang B, Gewirtz AT. MyD88-mediated TLR signaling protects against acute rotavirus infection while inflammasome cytokines direct Ab response. Innate Immun. 2015;21(4):416-28.

5. Sacramento L, Trevelin SC, Nascimento MS, Lima-Junior DS, Costa DL, Almeida RP, Cunha FQ, Silva JS, Carregaro V. Toll-like receptor 9 signaling in dendritic cells regulates neutrophil recruitment to inflammatory foci following Leishmania infantum infection. Infect Immun. 2015;83(12):4604-16.

6. Sturdevant GL, Caldwell HD. Innate immunity is sufficient for the clearance of Chlamydia trachomatis from the female mouse genital tract. Pathog Dis. 2014;72(1):70-3.

7. Callaway JB, Smith SA, McKinnon KP, de Silva AM, Crowe Jr JE, Ting JP. Spleen Tyrosine Kinase (Syk) mediates IL-1 beta induction by primary human monocytes during antibody-enhanced dengue virus infection. J Biol Chem. 2015;290(28):17306-20.

8. Stifter SA, Feng CG. Interfering with immunity: detrimental role of type I IFNs during infection. J Immunol. 2015;194(6):2455-65.

9. Starkhammar M, Kumlien Georen S, Dahlen SE, Cardell LO, Adner M. TNFalpha-blockade stabilizes local airway hyperresponsiveness during TLRinduced exacerbations in murine model of asthma. Respir Res. 2015;16:129. 
10. Lacerte P, Brunet A, Egarnes B, Duchene B, Brown JP, Gosselin J. Overexpression of TLR2 and TLR9 on monocyte subsets of active rheumatoid arthritis patients contributes to enhance responsiveness to TLR agonists. Arthritis Res Ther. 2016;18(1):10.

11. Kornalijnslijper E, Beerda B, Daemen I, van der Werf J, van Werven T, Niewold T, Rutten V, Noordhuizen-Stassen E. The effect of milk production level on host resistance of dairy cows, as assessed by the severity of experimental Escherichia coli mastitis. Vet Res. 2003;34(6):721-36.

12. Ballou MA. Growth and development symposium: inflammation: role in the etiology and pathophysiology of clinical mastitis in dairy cows. J Anim Sci. 2012;90(5):1466-78.

13. Petzl W, Gunther J, Pfister T, Sauter-Louis C, Goetze L, von Aulock S, HafnerMarx A, Schuberth HJ, Seyfert HM, Zerbe H. Lipopolysaccharide pretreatment of the udder protects against experimental Escherichia coli mastitis. Innate Immun. 2012;18(3):467-77.

14. Gunther J, Petzl W, Zerbe H, Schuberth HJ, Koczan D, Goetze L, Seyfert HM. Lipopolysaccharide priming enhances expression of effectors of immune defence while decreasing expression of pro-inflammatory cytokines in mammary epithelia cells from cows. BMC Genomics. 2012;13:17.

15. Glynn DJ, Hutchinson MR, Ingman W. Toll-like receptor 4 regulates lipopolysaccharide-induced inflammation and lactation insufficiency in a mouse model of mastitis. Biol Reprod. 2014;90(5):91.

16. Kandasamy S, Green BB, Benjamin AL, Kerr DE. Between-cow variation in dermal fibroblast response to lipopolysaccharide reflected in resolution of inflammation during Escherichia coli mastitis. J Dairy Sci. 2011;94(12):5963-75.

17. Benjamin AL, Green BB, Hayden LR, Barlow JW, Kerr DE. Cow-to-cow variation in fibroblast response to a toll-like receptor 2/6 agonist and its relation to mastitis caused by intramammary challenge with Staphylococcus aureus. J Dairy Sci. 2015;98(3):1836-50

18. Sharma BS, Abo-Ismail MK, Schenkel FS, You Q, Verschoor CP, Pant SD, Karrow NA. Association of TLR4 polymorphisms with Mycobacterium avium subspecies paratuberculosis infection status in Canadian Holsteins. Anim Genet. 2015;46(5):560-5.

19. Govignon-Gion A, Dassonneville R, Baloche G, Ducrocq V. Multiple trait genetic evaluation of clinical mastitis in three dairy cattle breeds. Animal. 2016;10(4):558-65.

20. Li J, Li R, Wang Y, Hu X, Zhao Y, Li L, Feng C, Gu X, Liang F, Lamont SJ, et al. Genome-wide DNA methylome variation in two genetically distinct chicken lines using MethylC-seq. BMC Genomics. 2015;16:851.

21. Green BB, Kerr DE. Epigenetic contribution to individual variation in response to lipopolysaccharide in bovine dermal fibroblasts. Vet Immunol Immunopathol. 2014;157(1-2):49-58.

22. Green BB, McKay SD, Kerr DE. Age dependent changes in the LPS induced transcriptome of bovine dermal fibroblasts occurs without major changes in the methylome. BMC Genomics. 2015;16:30.

23. Lents CA, Wettemann RP, Paape MJ, Vizcarra JA, Looper ML, Buchanan DS, Lusby KS. Efficacy of intramuscular treatment of beef cows with oxytetracycline to reduce mastitis and to increase calf growth. J Anim Sci. 2002;80(6):1405-12.

24. Persson Waller K, Persson Y, Nyman AK, Stengarde L. Udder health in beef cows and its association with calf growth. Acta Vet Scand. 2014:56:9.

25. Pena CJ, Neugut YD, Champagne FA. Developmental timing of the effects of maternal care on gene expression and epigenetic regulation of hormone receptor levels in female rats. Endocrinology. 2013;154(11):4340-51.

26. Benjamin AL, Green BB, Crooker BA, McKay SD, Kerr DE. Differential responsiveness of Holstein and Angus dermal fibroblasts to LPS challenge occurs without major differences in the methylome. BMC Genomics. 2016;17(1):258

27. Green BB, Kandasamy S, Elsasser TH, Kerr DE. The use of dermal fibroblasts as a predictive tool of the toll-like receptor 4 response pathway and its development in Holstein heifers. J Dairy Sci. 2011;94(11):5502-14.

28. Kanzleiter T, Jahnert M, Schulze G, Selbig J, Hallahan N, Schwenk RW, Schurmann A. Exercise training alters DNA methylation patterns in genes related to muscle growth and differentiation in mice. Am J Physiol Endocrinol Metab. 2015;308(10):E912-20.

29. da Huang W, Sherman BT, Lempicki RA. Systematic and integrative analysis of large gene lists using DAVID bioinformatics resources. Nat Protoc. 2009;4(1):44-57.

30. da Huang W, Sherman BT, Lempicki RA. Bioinformatics enrichment tools: paths toward the comprehensive functional analysis of large gene lists. Nucleic Acids Res. 2009;37(1):1-13.
31. Begue $G$, Raue U, Jemiolo B, Trappe SW. DNA Methylation assessment from human slow- and fast-twitch skeletal muscle fibers. J Appl Physiol (1985). 2017;122(4):952-967.

32. Pan $H$, Chen L, Dogra S, Teh AL, Tan JH, Lim Yl, Lim YC, Jin S, Lee YK, Ng PY, et al. Measuring the methylome in clinical samples: improved processing of the Infinium Human Methylation450 BeadChip Array. Epigenetics. 2012;7(10):1173-87.

33. Deaton $\mathrm{AM}, \mathrm{Bird} \mathrm{A}$. CpG islands and the regulation of transcription. Genes Dev. 2011;25(10):1010-22.

34. Franceschi C, Bonafe M, Valensin S, Olivieri F, De Luca M, Ottaviani E, De Benedictis $\mathrm{G}$. Inflamm-aging. An evolutionary perspective on immunosenescence. Ann N Y Acad Sci. 2000;908:244-54.

35. Baylis D, Bartlett DB, Patel HP, Roberts HC. Understanding how we age: insights into inflammaging. Longev Healthspan. 2013;2(1):8.

36. Nile CJ, Read RC, Akil M, Duff GW, Wilson AG. Methylation status of a single CpG site in the IL6 promoter is related to IL6 messenger RNA levels and rheumatoid arthritis. Arthritis Rheum. 2008;58(9):2686-93.

37. Gomes AV, de Souza Morais SM, Menezes-Filho SL, de Almeida LG, Rocha RP, Siqueira Ferreira JM, Dos Santos LL, Malaquias LC, Coelho LF. The demethylation profile of the TNF-alpha promoter gene is associated with high expression of this cytokine in Dengue virus patients. J Med Virol. 2016:88(8):1297-302.

38. Gowers IR, Walters K, Kiss-Toth E, Read RC, Duff GW, Wilson AG. Age-related loss of $\mathrm{CpG}$ methylation in the tumour necrosis factor promoter. Cytokine. 2011;56(3):792-7.

39. Takahashi K, Sugi Y, Hosono A, Kaminogawa S. Epigenetic regulation of TLR4 gene expression in intestinal epithelial cells for the maintenance of intestinal homeostasis. J Immunol. 2009;183(10):6522-9.

40. Doherty R, O'Farrelly C, Meade KG. Epigenetic regulation of the innate immune response to LPS in bovine peripheral blood mononuclear cells (PBMC). Vet Immunol Immunopathol. 2013;154(3-4):102-10.

41. Doherty R, Whiston R, Cormican P, Finlay EK, Couldrey C, Brady C, O'Farrelly C, Meade KG. The CD4(+) T cell methylome contributes to a distinct CD4(+) T cell transcriptional signature in Mycobacterium bovis-infected cattle. Sci Rep. 2016;6:31014.

42. Chang G, Petzl W, Vanselow J, Gunther J, Shen X, Seyfert HM. Epigenetic mechanisms contribute to enhanced expression of immune response genes in the liver of cows after experimentally induced Escherichia coli mastitis. Vet J. 2015;203(3):339-41.

43. Chang G, Zhang K, Xu T, Jin D, Guo J, Zhuang S, Shen X. Epigenetic mechanisms contribute to the expression of immune related genes in the livers of dairy cows fed a high concentrate diet. PLoS One. 2015;10(4):e0123942.

44. Bacalini MG, Friso S, Olivieri F, Pirazzini C, Giuliani C, Capri M, Santoro A, Franceschi C, Garagnani P. Present and future of anti-ageing epigenetic diets. Mech Ageing Dev. 2014;136-137:101-15.

45. Marttila S, Kananen L, Hayrynen S, Jylhava J, Nevalainen T, Hervonen A, Jylha M, Nykter M, Hurme M. Ageing-associated changes in the human DNA methylome: genomic locations and effects on gene expression. BMC Genomics. 2015;16:179.

46. van Delft MA, Huitema LF, Tas SW. The contribution of NF-kappaB signalling to immune regulation and tolerance. Eur J Clin Invest. 2015;45(5):529-39.

47. Ettou S, Humbrecht C, Benet B, Billot K, d'Allard D, Mariot V, Goodhardt M Kosmider O, Mayeux P, Solary E, et al. Epigenetic control of NF-kappaBdependent FAS gene transcription during progression of myelodysplastic syndromes. Mol Cancer Res. 2013:11(7):724-35.

48. Wen AY, Sakamoto KM, Miller LS. The role of the transcription factor CREB in immune function. J Immunol. 2010;185(11):6413-9.

49. Koga Y, Hisada T, Ishizuka T, Utsugi M, Ono A, Yatomi M, Kamide Y, AokiSaito $H$, Tsurumaki $H$, Dobashi $K$, et al. CREB regulates TNF-alpha-induced GM-CSF secretion via p38 MAPK in human lung fibroblasts. Allergol Int. 2016;65(4):406-13.

50. Lee GL, Wu JY, Yeh CC, Kuo CC. TLR4 induces CREB-mediated IL-6 production via upregulation of F-spondin to promote vascular smooth muscle cell migration. Biochem Biophys Res Commun. 2016:473(4):1205-10.

51. Thakur BK, Dasgupta N, Ta A, Das S. Physiological TLR5 expression in the intestine is regulated by differential DNA binding of Sp1/Sp3 through simultaneous Sp1 dephosphorylation and Sp3 phosphorylation by two different PKC isoforms. Nucleic Acids Res. 2016:44(12):5658-72.

52. Wang B, Rao YH, Inoue M, Hao R, Lai CH, Chen D, McDonald SL, Choi MC, Wang Q. Shinohara ML, et al. Microtubule acetylation amplifies p38 kinase signalling and anti-inflammatory IL-10 production. Nat Commun. 2014;5:3479. 
53. Keestra-Gounder AM, Byndloss MX, Seyffert N, Young BM, Chavez-Arroyo A, Tsai AY, Cevallos SA, Winter MG, Pham OH, Tiffany CR, et al. NOD1 and NOD2 signalling links ER stress with inflammation. Nature. 2016;532(7599):394-7.

54. Mohammed-Ali Z, Cruz GL, Dickhout JG. Crosstalk between the unfolded protein response and NF-kappaB-mediated inflammation in the progression of chronic kidney disease. J Immunol Res. 2015:2015:428508.

55. Labzin LI, Schmidt SV, Masters SL, Beyer M, Krebs W, Klee K, Stahl R, Lutjohann D, Schultze JL, Latz E, et al. ATF3 is a key regulator of macrophage IFN responses. J Immunol. 2015;195(9):4446-55.

56. Weldon AJ, Moldovan I, Cabling MG, Hernandez EA, Hsu S, Gonzalez J, Parra A, Benitez A, Daoud N, Colburn K, et al. Surface APRIL is elevated on myeloid cells and is associated with disease activity in patients with rheumatoid arthritis. J Rheumatol. 2015;42(5):749-59.

57. Sandberg WJ, Otterdal K, Gullestad L, Halvorsen B, Ragnarsson A, Froland SS, Damas JK, Oie E, Aukrust P, Hansson GK, et al. The tumour necrosis factor superfamily ligand APRIL (TNFSF13) is released upon platelet activation and expressed in atherosclerosis. Thromb Haemost. 2009;102(4):704-10.

58. Salazar-Camarena DC, Ortiz-Lazareno PC, Cruz A, Oregon-Romero E, Machado-Contreras JR, Munoz-Valle JF, Orozco-Lopez M, Marin-Rosales M, Palafox-Sanchez CA. Association of BAFF, APRIL serum levels, BAFF-R, TACI and BCMA expression on peripheral B-cell subsets with clinical manifestations in systemic lupus erythematosus. Lupus. 2016;25(6):582-92.

59. Alexaki VI, Pelekanou V, Notas G, Venihaki M, Kampa M, Dessirier V, SabourAlaoui S, Stathopoulos EN, Tsapis A, Castanas E. B-cell maturation antigen (BCMA) activation exerts specific proinflammatory effects in normal human keratinocytes and is preferentially expressed in inflammatory skin pathologies. Endocrinology. 2012;153(2):739-49.

60. Lee SM, Kim EJ, Suk K, Lee WH. BAFF and APRIL induce inflammatory activation of THP-1 cells through interaction with their conventional receptors and activation of MAPK and NF-kappaB. Inflamm Res. 2011;60(9):807-15.

61. Cheung LW, Walkiewicz KW, Besong TM, Guo H, Hawke DH, Arold ST, Mills GB. Regulation of the PI3K pathway through a p85alpha monomerhomodimer equilibrium. Elife. 2015:4:e06866.

62. Williams DL, Li CF, Ha TZ, Ozment-Skelton T, Kalbfleisch JH, Preiszner J, Brooks L, Breuel K, Schweitzer JB. Modulation of the phosphoinositide innate resistance to polymicrobial 3-kinase pathway alters sepsis. J Immunol. 2004;172(1):449-56.

63. Kok BP, Saez E. Activating PI3-kinase to dampen inflammation. Chem Biol. 2014;21(8):917-8.

64. Hawkins PT, Stephens LR. PI3K signalling in inflammation. Biochim Biophys Acta. 2015;1851(6):882-97.

65. Zanoni I, Ostuni R, Capuano G, Collini M, Caccia M, Ronchi AE, Rocchetti M, Mingozzi F, Foti M, Chirico G, et al. CD14 regulates the dendritic cell life cycle after LPS exposure through NFAT activation. Nature. 2009;460(7252):264-8.

66. Yarilina A, Xu K, Chen J, Ivashkiv LB. TNF activates calcium-nuclear factor of activated T cells (NFAT)c1 signaling pathways in human macrophages. Proc Natl Acad Sci U S A. 2011;108(4):1573-8.

67. Suehiro J, Hamakubo T, Kodama T, Aird WC, Minami T. Vascular endothelia growth factor activation of endothelial cells is mediated by early growth response-3. Blood. 2010;115(12):2520-32.

68. Stringhini S, Polidoro S, Sacerdote C, Kelly RS, van Veldhoven K, Agnoli C, Grioni S, Tumino R, Giurdanella MC, Panico S, et al. Life-course socioeconomic status and DNA methylation of genes regulating inflammation. Int J Epidemiol. 2015:44(4):1320-30.

69. Stringhini S, Zaninotto P, Kumari M, Kivimaki M, Batty GD. Lifecourse socioeconomic status and type 2 diabetes: the role of chronic inflammation in the English Longitudinal Study of Ageing. Sci Rep. 2016;6:24780.

70. Cai D, Yuan M, Liu H, Han Z, Pan S, Yang Y, Zhao R. Epigenetic and SP1-mediated regulation is involved in the repression of galactokinase 1 gene in the liver of neonatal piglets born to betaine-supplemented sows. Eur J Nutr. 2016:[Epub ahead of print].

71. Gopisetty G, Xu J, Sampath D, Colman H, Puduvalli VK. Epigenetic regulation of CD133/PROM1 expression in glioma stem cells by Sp1/myc and promoter methylation. Oncogene. 2013;32(26):3119-29.

72. Zhang $X$, Yang $R$, Jia $Y$, Cai $D$, Zhou B, Qu X, Han H, Xu L, Wang L, Yao $Y$, et al. Hypermethylation of Sp1 binding site suppresses hypothalamic POMC in neonates and may contribute to metabolic disorders in adults: impact of maternal dietary CLAs. Diabetes. 2014;63(5):1475-87.
73. Rudolf R, Busch R, Patra AK, Muhammad K, Avots A, Andrau JC, KleinHessling S, Serfling E. Architecture and expression of the nfatc1 gene in lymphocytes. Front Immunol. 2014;5:21.

74. Hellwig S, Miduturu CV, Kanda S, Zhang J, Filippakopoulos P, Salah E, Deng $X$, Choi HG, Zhou W, Hur W, et al. Small-molecule inhibitors of the C-Fes protein-tyrosine kinase. Chem Biol. 2012;19(4):529-40.

75. Smith JA, Samayawardhena LA, Craig AW. Fps/Fes protein-tyrosine kinase regulates mast cell adhesion and migration downstream of Kit and beta1 integrin receptors. Cell Signal. 2010;22(3):427-36.

76. Tan BL, Yazicioglu MN, Ingram D, McCarthy J, Borneo J, Williams DA, Kapur R. Genetic evidence for convergence of c-Kit- and alpha4 integrin-mediated signals on class IA Pl-3kinase and the Rac pathway in regulating integrindirected migration in mast cells. Blood. 2003;101(12):4725-32.

77. Barra MM, Richards DM, Hansson J, Hofer AC, Delacher M, Hettinger J, Krijgsveld J, Feuerer M. Transcription factor 7 limits regulatory T cell generation in the thymus. J Immunol. 2015;195(7):3058-70.

78. van Eijk KR, de Jong S, Boks MP, Langeveld T, Colas F, Veldink JH, de Kovel CG, Janson E, Strengman E, Langfelder P, et al. Genetic analysis of DNA methylation and gene expression levels in whole blood of healthy human subjects. BMC Genomics. 2012;13:636.

79. Vu TH, Li T, Hoffman AR. Promoter-restricted histone code, not the differentially methylated DNA regions or antisense transcripts, marks the imprinting status of IGF2R in human and mouse. Hum Mol Genet. 2004; 13(19):2233-45.

80. Cook DN, Kang HS, Jetten AM. Retinoic Acid-Related Orphan Receptors (RORs): Regulatory Functions in Immunity, Development, Circadian Rhythm, and Metabolism. Nucl Receptor Res. 2015;2:101185.

81. Halim TY, MacLaren A, Romanish MT, Gold MJ, McNagny KM, Takei F. Retinoic-acid-receptor-related orphan nuclear receptor alpha is required for natural helper cell development and allergic inflammation. Immunity. 2012; 37(3):463-74

82. Kang HS, Okamoto K, Takeda Y, Beak JY, Gerrish K, Bortner CD, DeGraff LM, Wada T, Xie W, Jetten AM. Transcriptional profiling reveals a role for RORalpha in regulating gene expression in obesity-associated inflammation and hepatic steatosis. Physiol Genomics. 2011;43(13):818-28.

83. Blattler A, Yao L, Witt H, Guo Y, Nicolet CM, Berman BP, Farnham PJ. Global loss of DNA methylation uncovers intronic enhancers in genes showing expression changes. Genome Biol. 2014;15(9):469.

84. Pareek R, Wellnitz O, Van Dorp R, Burton J, Kerr D. Immunorelevant gene expression in LPS-challenged bovine mammary epithelial cells. J Appl Genet. 2005;46(2):171-7.

\section{Submit your next manuscript to BioMed Central and we will help you at every step:}

- We accept pre-submission inquiries

- Our selector tool helps you to find the most relevant journal

- We provide round the clock customer support

- Convenient online submission

- Thorough peer review

- Inclusion in PubMed and all major indexing services

- Maximum visibility for your research

Submit your manuscript at www.biomedcentral.com/submit 